\title{
Towards risk-based flood management in highly productive paddy rice cultivation - concept development and application to the Mekong Delta
}

\author{
Nguyen Van Khanh Triet ${ }^{1,2}$, Nguyen Viet Dung ${ }^{1}$, Bruno Merz $^{1,3}$, and Heiko Apel ${ }^{1}$ \\ ${ }^{1}$ GFZ German Research Centre for Geosciences, Section 5.4 Hydrology, Potsdam, 14473, Germany \\ ${ }^{2}$ SIWRR Southern Institute of Water Resources Research, Ho Chi Minh City, Vietnam \\ ${ }^{3}$ Institute of Earth and Environmental Science, University of Potsdam, Potsdam, 14476, Germany
}

Correspondence: Nguyen Van Khanh Triet (triet@gfz-potsdam.de)

Received: 25 July 2018 - Discussion started: 6 August 2018

Accepted: 14 October 2018 - Published: 5 November 2018

\begin{abstract}
Flooding is an imminent natural hazard threatening most river deltas, e.g. the Mekong Delta. An appropriate flood management is thus required for a sustainable development of the often densely populated regions. Recently, the traditional event-based hazard control shifted towards a risk management approach in many regions, driven by intensive research leading to new legal regulation on flood management. However, a large-scale flood risk assessment does not exist for the Mekong Delta. Particularly, flood risk to paddy rice cultivation, the most important economic activity in the delta, has not been performed yet. Therefore, the present study was developed to provide the very first insight into delta-scale flood damages and risks to rice cultivation. The flood hazard was quantified by probabilistic flood hazard maps of the whole delta using a bivariate extreme value statistics, synthetic flood hydrographs, and a large-scale hydraulic model. The flood risk to paddy rice was then quantified considering cropping calendars, rice phenology, and harvest times based on a time series of enhanced vegetation index (EVI) derived from MODIS satellite data, and a published rice flood damage function. The proposed concept provided flood risk maps to paddy rice for the Mekong Delta in terms of expected annual damage. The presented concept can be used as a blueprint for regions facing similar problems due to its generic approach. Furthermore, the changes in flood risk to paddy rice caused by changes in land use currently under discussion in the Mekong Delta were estimated. Two land-use scenarios either intensifying or reducing rice cropping were considered, and the changes in risk were presented in spatially explicit flood risk maps. The ba-
\end{abstract}

sic risk maps could serve as guidance for the authorities to develop spatially explicit flood management and mitigation plans for the delta. The land-use change risk maps could further be used for adaptive risk management plans and as a basis for a cost-benefit of the discussed land-use change scenarios. Additionally, the damage and risks maps may support the recently initiated agricultural insurance programme in Vietnam.

\section{Introduction}

Characterized by low topography, the Mekong Delta (MD) is subjected to flooding caused by high river discharge, tidal backwater effects, and storm surges. Floods in the Mekong Delta are annual events, mainly triggered by the Asian monsoons, but also by tropical cyclones (typhoons). On the positive side, floods bring various benefits to the MD with an estimated annual value of USD 8-10 billion (MRC, 2012). These benefits include provision of sediment to counter delta subsidence, increase in wild fish catch and enhancement of soil fertility through deposited sediment (Manh et al., 2014). On the other hand, extreme floods can result in extensive damages as recorded during the floods in 2011 and 2000. For example, the 2000 flood, considered as a 20 -year flood (Le et al., 2007), resulted in over 450 fatalities and economic losses of USD 250 million (MRC, 2012). Recent studies suggest that the frequency of such extreme events is likely to increase (Delgado et al., 2010; Hirabayashi et al., 2013). For instance, the 100-year flood in the Mekong basin in the 20th 
century is projected to occur every $10-20$ years in the 21 st century due to impacts of climate change (Hirabayashi et al., 2013). Therefore, assessing hazards and risks induced by extreme floods is a crucial task for developing flood management strategies and climate change adaptation measures.

Traditionally, flood management in the Vietnamese Mekong Delta (VMD) has focussed on engineering solutions aiming at flood control. Structural flood defence measures, such as sluice gates and dyke lines, were implemented across the whole delta. The water level of the flood in 2000 was commonly chosen as the design flood event. Flood risk assessments, taking into account not only flood probabilities and water levels, but also flood losses, were not undertaken to support flood management. Recently, non-structural measures (e.g. shifting of cropping calendar) have gained more interest. This alteration is in agreement with the global trend of moving from flood hazard control toward flood risk management (Merz et al., 2010). By definition, risk assessment is the evaluation of the frequency and magnitude of floods, or flood hazard, and their consequences. Hence, damage assessment is an essential task for the transition from traditional hazard control to flood risk management.

The majority of the literature on flood hazard assessments for the VMD focusses on changes in delta inundation hazards driven by upstream infrastructure development (e.g. hydropower dams), local flood control (e.g. dyke systems), climate change impacts, and sea level rise by hydrodynamic modelling (Le et al., 2007; Van, 2009; Dinh et al., 2012; Van et al., 2012; Toan, 2014; Triet et al., 2017; Dang et al., 2018). A comprehensive flood hazard analysis for the whole MD can only be found in the study of Dung et al. (2015). They developed different copula-based bivariate statistical models to quantify the probability of joint occurrence of peak discharge and flood volume of the Mekong River at Kratie, commonly defined as the upstream entrance of the MD. Apel et al. (2016) presented a detailed probabilistic fluvial-pluvial flood hazard assessment for the city of Can Tho in the centre of VMD using the results of Dung et al. (2015) as a boundary condition for a fluvial 2-D urban flood model.

Studies on flood damage are rare for the VMD. Damage assessments require rather extensive data sets, such as landuse, cropping systems and crop timing, asset values, damage functions for the different land-use types, and damage data to calibrate and validate the damage models. Consequently, flood damage and risk assessments have been conducted on the scale of districts or provinces only. For example, Chinh et al. (2017) developed a model to estimate flood losses using surveyed damage data of the flood in 2011 and assessed flood risk for an urban district of Can Tho city. Similarly, publications on agro-economic flood damage are practically non-existent for the VMD. The literature search on damage to agriculture in the VMD resulted in a single publication, a report by the Mekong River Commission (MRC, 2009). The MRC developed a loss model for paddy rice in two provinces in the VMD: An Giang and Dong Thap. Two damage func- tions were developed using observed maximum water levels at two gauging stations, and statistical damage data for the period of 2000-2007. These depth-damage functions were then applied to estimate flood losses for the period 19102006. Since this model requires only the water level as input, it can provide a quick assessment of flood damage to rice crops. Applying these damage functions to the current situation is, however, not recommended due to the massive changes in land use and cropping system over the last two decades. For example, Le et al. (2018) calculated an annual rate of change in land use in the VMD of $14.9 \%$ during 2001-2012. Hence, to our best knowledge, large-scale economic assessments of flood damage to agriculture crops for the whole delta and appropriate damage models are missing.

Against this background, we provide the first large-scale flood risk assessment for the agricultural sector covering the whole VMD. Our assessment is focussed on paddy rice, the predominant land-use type in the delta. We limit our calculation to direct losses, i.e. yield reduction as consequence of physical contact with floodwater. The methodological novelty is the detailed consideration of cropping calendar and plant phenology in combination with synthetic probabilistic flood hydrographs mapping different flood regimes of the Mekong. By this, the important aspect of plant phenology and temporal occurrence of flood peaks is introduced into the probabilistic flood risk assessment approach.

The flood hazard is quantified following the methodology of Dung et al. (2015). To obtain spatially explicit flood hazard maps, a large-scale hydraulic inundation model is driven by synthetic flood discharge time series, which are associated with probabilities of occurrences. Based on these hazard maps, crop damages are estimated using published damage functions, and explicitly considering the temporal occurrence of high water levels, the cropping calendar, and plant phenology. Finally, the consequences of two land-use development scenarios proposed in the Mekong Delta Plan were estimated in terms of crop damages by floods.

\section{Study area and data}

\subsection{Study area}

The VMD covers an area of approximately $40500 \mathrm{~km}^{2}$ in the south of Vietnam, where the Mekong River discharges into the South China Sea through a number of estuary branches. The landscape is dominated by flat floodplains formed by deposited river sediments. Floodplain sedimentation is estimated to approximately $9.5 \mathrm{~mm} \mathrm{yr}^{-1}$ on average (Manh et al., 2013). The properties of the deposits and the associated nutrients in combination with the tropical climate form ideal conditions for high agricultural productivity. Official statistics indicate that over $64 \%$ of the delta (2.6 million ha) is used for agriculture, with rice as the dominant crop (threequarters of the total cultivation land), followed by orchard 


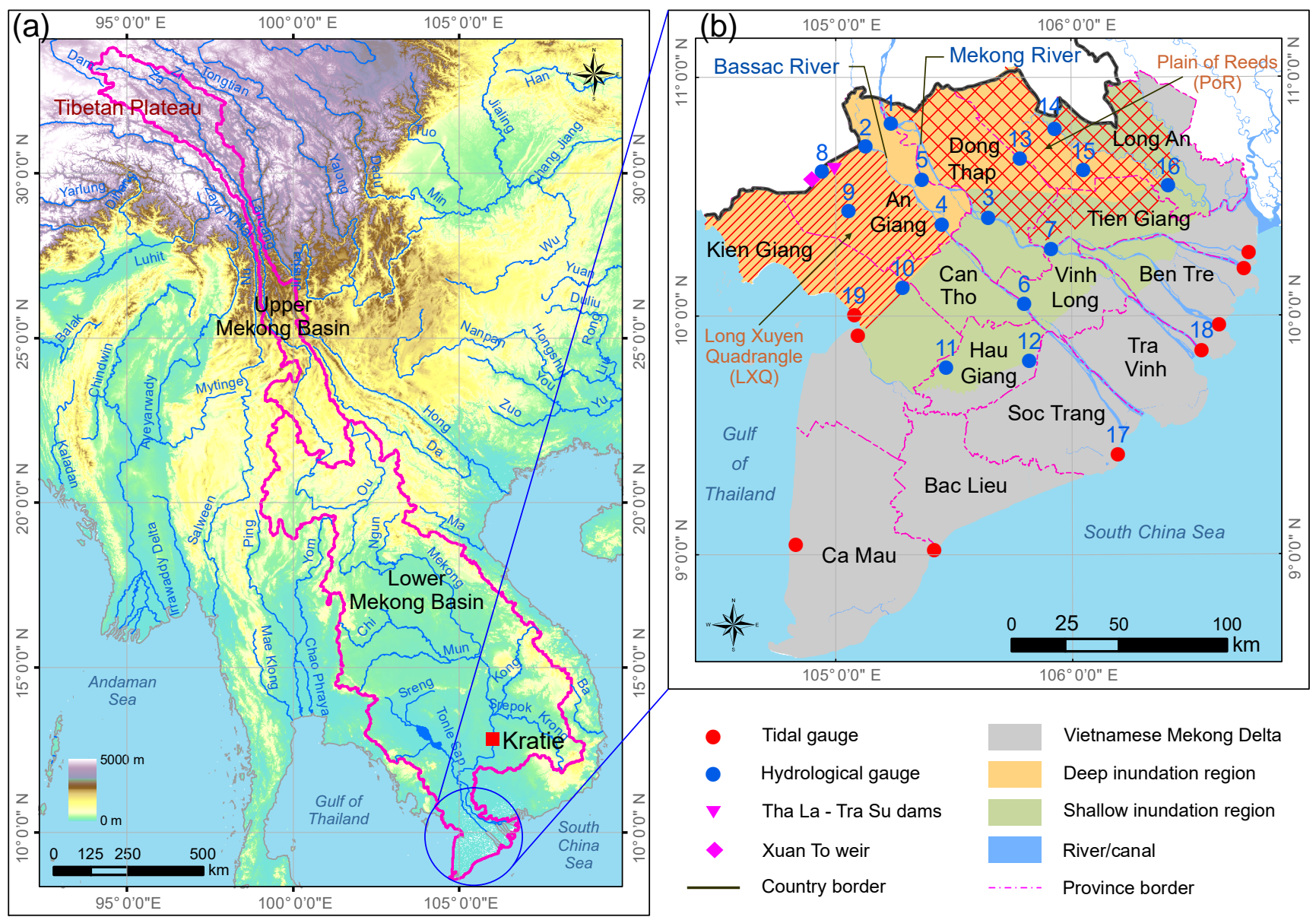

Figure 1. Geographical location of the Mekong Basin (a). The Vietnamese Mekong Delta and its flood-prone area (b). Deep-inundation region (above $1.5 \mathrm{~m}$ ) marked in yellow, shallow-inundation region (below $1.5 \mathrm{~m}$ ) presented in green. Red dots are locations of tidal gauges. Blue dots are locations of water level gauges. The numbers above blue and red dots present station codes.

farms and sugar cane (GSO, 2015). Covering only $12 \%$ of the total land area of Vietnam, the delta contributes $52 \%$ to the national food production and over $80 \%$ to the Vietnamese rice export (GSO, 2015).

From July to December, high discharge of the Mekong River triggered by the Asian monsoons cause a large-scale inundation in the delta. Our study area, referred to as the delta flood-prone region in Vietnam, comprises 2 million hectares of nine provinces. The area is commonly divided into two ecological regions on the basis of inundation depth, named "deep inundation" (above $1.5 \mathrm{~m}$ ) and "shallow inundation" (below $1.5 \mathrm{~m}$ ). The deep-inundation areas (marked in yellow in Fig. 1) encompass the two most important floodplains in the delta, i.e. the Plain of Reeds (PoR), and the Long Xuyen Quadrangle (LXQ).

Flooding in the VMD is characterized by slowly rising and receding rates, with a mean value of $5-10 \mathrm{~cm} \mathrm{day}^{-1}$. The flood hydrograph at Tan Chau and Chau Doc (blue points 1 and 2 in Fig. 1) usually has two peaks. The first peak nor- mally falls from mid-July to mid-August. The second, often higher peak, arrives from September to October. Floodwater from Cambodia enters the VMD via three main routes. The mainstream branches of the Mekong, i.e. Mekong and Bassac rivers, convey $90 \%$ of the total flood volume. The remaining $10 \%$ are the transboundary overland flow from Cambodian lowlands to the PoR east of the Mekong River, and the LXQ west of the Bassac River (Hung et al., 2012; Tri, 2012). Besides inundation caused by high river discharge, tidal floods occur in the vicinity of rivers/canals in the coastal areas, characterized by short but repeated durations following the high tides of the South China Sea and the Gulf of Thailand (Apel et al., 2016). 

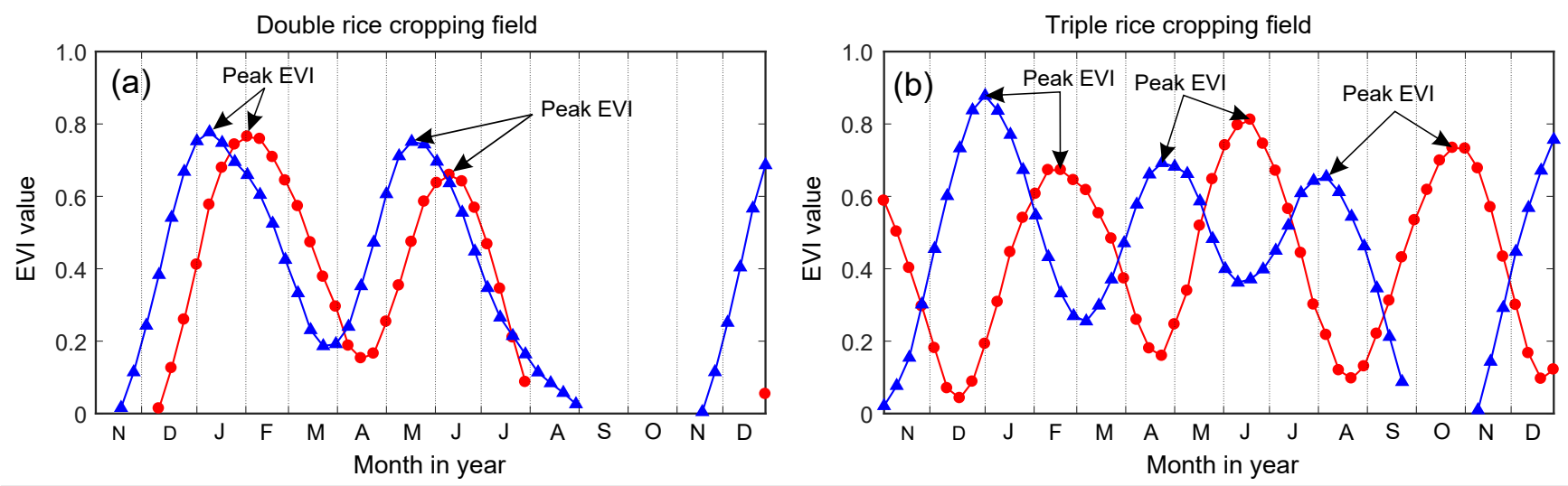

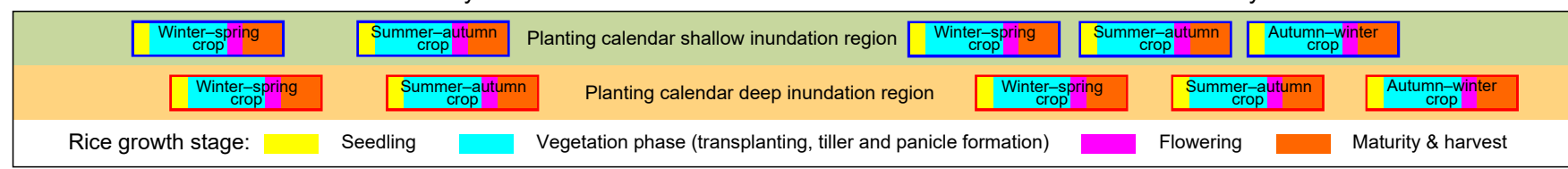

Figure 2. Time series of the smoothed enhanced vegetation index (EVI) for double (a) and triple (b) rice cropping fields in the Vietnamese Mekong Delta. The blue lines denote paddy fields in the shallow-inundation zone. Red lines represent paddy fields in the deep-inundation zone. The cropping season ends 40 days after the EVI peak (Kotera et al., 2016).

\subsection{Data}

\subsubsection{Topography data, tidal levels and operation schemes of flood control structures}

Tidal level data are used as downstream boundary condition of the flood propagation model. Hourly tidal level records at 10 gauge stations were collected, covering the entire flood season of the year 2011 from 1 June to 30 November. The locations of these tidal gauges are given in Fig. 1. These data were provided by the Southern Regional HydroMeteorology Centre of Vietnam (SHRMC). To generate inundation maps, a high-resolution $(5 \times 5 \mathrm{~m})$ lidar-based digital elevation model (DEM) for the whole VMD was acquired from the Ministry of Environment and Natural Resources of Vietnam (MONRE). The lidar data were collected and processed during 2009-2010. Operation schemes of the flood control structures in 2011 were collected from the Departments of Agriculture and Rural Development (DARD) of the delta provinces.

\subsubsection{Rice cropping system and planting calendar}

The rice cropping system in the VMD is strongly related to water availability, soil fertility and irrigation/drainage facilities (e.g. flood control structures). Rice fields are generally encircled by dyke systems to protect them against the regular flood pulse of the Mekong. These dyke systems can be classified as low dykes and high dykes. Low dykes protect the summer-autumn crop against the early flood peak from midJuly to mid-August. They are regularly overtopped during the later stages of the flood period. Farmlands protected by high dykes can be, however, completely cut off from floodwater. The design level of the dykes was chosen to withstand water levels observed during the historical flood in 2000 (Triet et al., 2017). The inundation of those areas is thus controlled by the operation of sluice gates included in the dyke lines.

Traditionally, farmers were only able to grow a single rice crop per year during the wet season. This crop was known as rainfed crop. Today, the majority of rainfed crops have been replaced by irrigated rice, except for small areas affected by saline water intrusion or poor soil quality (acid sulphate soil). Farmers are able to grow two or even three crops per year. One crop is planted in the dry season in NovemberDecember and harvested in February-March (called winterspring crop or Đông Xuân). During the wet season, farmers plant one or two crops. The first crop (summer-autumn crop or Hè Thu) is planted in April-early June and harvested by July-early August. The second crop (autumnwinter crop or Thu Đông) depends on how farmlands are protected against floodwater. Farmlands with full protection (located in the deep-inundation region) plant in August and harvest in November-December. In the shallow-inundation region, farmers harvest in late August-early September, before the arrival of the main flood peak.

The rice cropping system and planting calendar in the VMD have been well studied using optical and radar satellite data (e.g. Bouvet et al., 2009; Bouvet and Le Toan, 2011; Nguyen et al., 2015). Figure 2 illustrates the planting calendar in 2011 for four paddy fields positioned in the deep versus shallow-inundation region for double- and triple-season rice fields. There is a shift of 1-1.5 months in the planting calendar between the shallow- and deep-inundation regions. The enhanced vegetation index (EVI) time series used to con- 


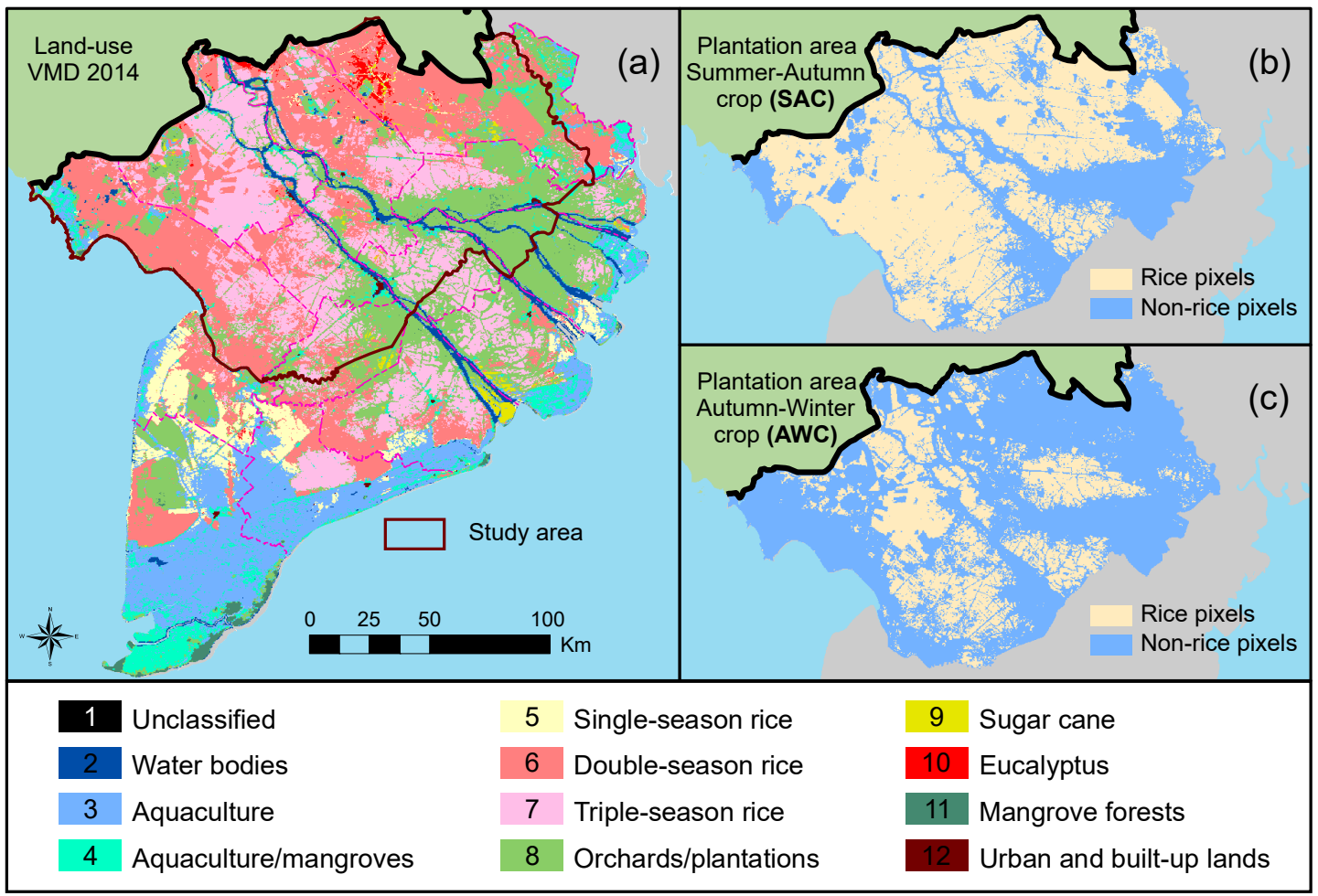

Figure 3. Panel (a) presents the land-use map of the Vietnamese Mekong Delta in 2014. Panels (b) and (c) show plantation areas of the summer-autumn crop (SAC) and the autumn-winter crop (AWC).

struct this plot were provided by Akihiko Kotera (personal communication, 1 March 2017). An EVI value of 0 indicates no vegetation cover, whereas a value of 1 means complete vegetation cover. The methodology used to derive the data set has been presented in Kotera et al. (2016) and applied to assess economic flood damage to rice crop in the Chao Phraya delta in Thailand from 2000 to 2011.

\subsubsection{Land-use data}

The land-use map of 2014, with a resolution of $250 \times$ $250 \mathrm{~m}$, covering all 13 provinces in the VMD was provided by the German Aerospace Centre (DLR). The VMD land use is part of the product MEKONG LC2010, covering the entire Mekong Basin at a spatial resolution of $500 \mathrm{~m}$. MEKONG LC2010 was developed within the GermanVietnamese project "Water-related Information System for a Sustainable Development of the Mekong Delta" (WISDOM, http://www.wisdom.eoc.dlr.de/, last access: 20 July 2018). Land cover data were derived using the Moderate Resolution Imaging Spectroradiometer (MODIS) instrument aboard the Terra and Aqua satellites. Different MODIS products were combined to provide cloud free composites. The enhanced vegetation index (EVI) was calculated following Eq. (1).

$\mathrm{EVI}=G \times \frac{\mathrm{NIR}-\mathrm{RED}}{\mathrm{NIR}+C_{1} \cdot \mathrm{RED}-C_{2} \cdot \mathrm{BLUE}+L}$, where $G$ is the gain factor $(G=2.5) . C_{1}$ and $C_{2}$ are the coefficients of the aerosol resistance term, which uses the $500 \mathrm{~m}$ blue band of MODIS to correct aerosol influences on the red band $\left(C_{1}=6.0\right.$ and $\left.C_{2}=7.5\right)$. $\mathrm{L}$ is the canopy background adjustment $(L=1)$ (Huete et al., 2002).

Land-use classification was performed on the basis of the EVI time series from 2001 to 2011 (for a detailed description see Leinenkugel et al. (2013). Within the 12 classes of the VMD land-use raster, three classes indicate rice cultivation areas: single-season rice, double-season rice, and tripleseason rice (values 5-7 in Fig. 3a).

We reclassified the original product to two raster images presenting the summer-autumn crop, hereafter referred as SAC, and the autumn-winter crop, hereafter referred to as AWC, since their growth stages partially or fully fall in the flood season. The SAC image was created by merging all pixels with double-season and triple-season rice. The other landuse classes (e.g. orchards, sugar cane) were considered nonrice pixels (presented in Fig. 3b). To produce the AWC image, which is only grown in triple-season cropping schemes, only pixels with original values of 7 were considered (see Fig. 3c). 

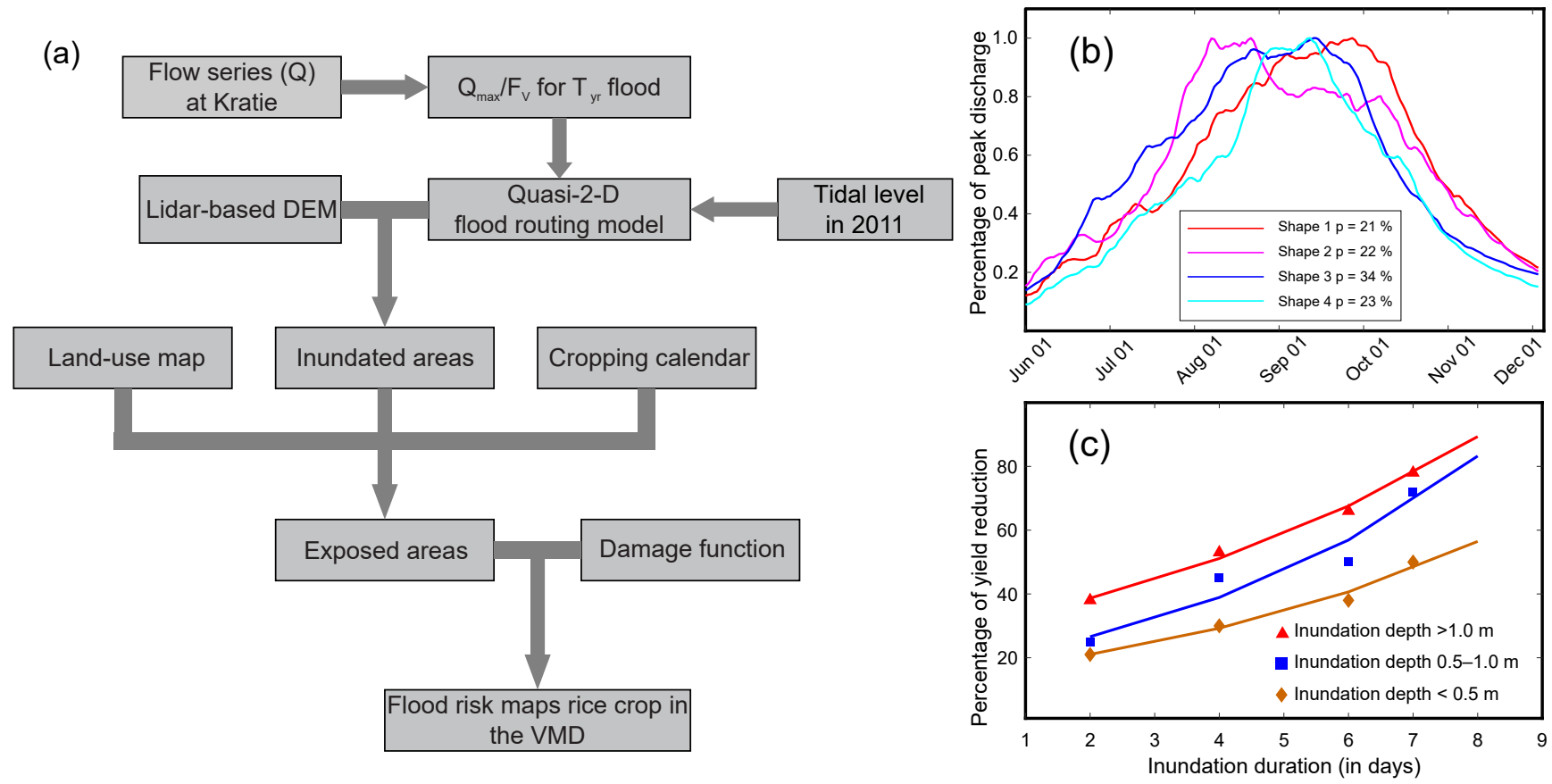

Figure 4. (a) Procedure for estimating flood risk to rice production in the Vietnamese Mekong Delta. (b) The four normalized discharge hydrographs at Kratie, together with their probability of occurrence (Dung et al., 2015) used for the derivation of synthetic flood events as the upper boundary of the hydraulic model. (c) Stage-damage curve for paddy rice (Dutta et al., 2003).

\section{Methodology}

For the large-scale flood risk assessment, the temporal relationship between the inundation hazard and the rice planting calendar was taken into consideration. The next sections describe the procedure that derives the area of rice crops exposed to floods, flood damage $(D)$ from a given extreme event, and the expected annual damage (EAD). These risk indicators were estimated for the current situation and for two land-use development scenarios, namely the reduction or expansion of the triple-season rice area as given in the Mekong Delta Plan of the Vietnamese government. The methodology is outlined in Fig. 4a.

\subsection{Determining event hydrographs corresponding to the $T$-year flood}

Synthetic flood events were estimated for station Kratie (Fig. 1, left panel) with 10-, 20-, 50-, and 100-year return periods, referred to as $T_{10}, T_{20}, T_{50}$, and $T_{100}$. This station is commonly defined as the upstream entrance of the MD and is used as upper boundary of the hydraulic inundation model of the MD. The estimation of flood events is based on Dung et al. (2015). The authors developed and tested different bivariate copula-based statistical models on extreme values, using annual maximum discharge $Q_{\max }$ and flood volume $F_{V}$. Both variables are important for the characterization of the long-lasting annual floods in the MD. From different models that were tested, the Gumbel-Hougaard copula was selected as most suitable, with log-normal distributions describing the marginals of $Q_{\max }$ and $F_{V}$. The outcomes of the mentioned study is the very first publication on flood frequency analysis for the MD, considering both peak discharge and flood volume. We refer readers to the original paper for a detailed description.

Four pairs of peak discharge $\left(Q_{\max }\right)$ and volume at Kratie $\left(F_{V}\right)$, corresponding to $T_{10}, T_{20}, T_{50}$ and $T_{100}$ floods were selected from the bivariate copula model. The most probable pairs were selected from the $Q_{\max } / F_{V}$ pairs with equal joint probabilities corresponding to the return periods specified above. A full probabilistic analysis using a large number of $Q_{\max } / F_{V}$ pairs with equal joint probabilities was not performed due to the high computational demand of the largescale hydraulic model (on average, $2-3 \mathrm{~h}$ are required for one simulation of the whole flood season June-November on a PC installed with Intel i7-CPU 3.0 GHz, 16 GB RAM). The selected $Q_{\max }$ and $F_{V}$ values range from 56500 to $66000 \mathrm{~m}^{3} \mathrm{~s}^{-1}$ and from 459 to $525 \mathrm{~km}^{3}$, from the different return periods.

Damages to agriculture crops are highly dependent on the time of occurrence of flooding (Penning-Rowsell et al., 2003; Förster et al., 2008; Klaus et al., 2016). To account for the timing, each of the four $Q_{\max } / F_{V}$ pairs were scaled to synthetic flood hydrographs covering the whole flood season from 1 June to 30 November using four typical hydrograph shapes $\left(\operatorname{shp}_{i}, i=1-4\right)$, representing different flood patterns 
and, consequently, different possible damages. These shapes were adapted from Dung et al. (2015) (see Fig. 4b). The shape $\operatorname{shp}_{3}$ has the highest possibility of occurrence ( $p=$ 0.34). The flood in 2000 closely followed this shape, with a minor alteration as the first peak arrived some days earlier. The other three hydrograph shapes have equal probabilities of occurrence ( $p=0.21-0.23)$. The shape $\mathrm{shp}_{2}$ has an early flood peak, while $\operatorname{shp}_{1}$ shows a late peak. The disastrous flood in 2011 resembled $\operatorname{shp}_{1}$.

This procedure results in 16 synthetic discharge time series at Kratie. They serve as the upper boundary condition for the flood propagation model. In each simulation, the lower boundaries (i.e. tidal levels), dyke scenarios and operation schemes of flood control structures were fixed as recorded in 2011, i.e. the most recent damaging flood. The scenarios are denoted using the return period and the hydrograph shape. For example, scenario $T_{100} \operatorname{shp}_{3}$ corresponds to the 100-year return period of $Q_{\max } / F_{V}$ and the hydrograph $\mathrm{shp}_{3}$.

\subsection{Transformation of discharge to water levels}

To transform the discharge series into spatially distributed inundation water levels and associated timing in the VMD, a quasi-2-D, large-scale hydraulic model was used. The model domain covers the entire MD, including the VMD and Cambodia lowlands and the Tonle Sap Lake. It uses Kratie as the upper boundary condition and the tidal level monitoring gauges along the South China Sea and the Gulf of Thailand as downstream boundaries.

The model was initially developed by Dung et al. (2011), using the 1-D river model modelling package MIKE11-HD developed by Danish Hydraulic Institute (DHI). The hydrodynamic module (HD) provides the full dynamic solution of the 1-D Saint-Venant equations. The solution is based on an implicit finite difference scheme developed by Abbott and Ionescu (1967). Floodplain inundation (2-D flow) was presented by the 1-D model through wide cross sections for the Cambodian part of the model domain, which is appropriate for the comparatively low anthropogenic impacts on the channel network, and natural inundation dynamics of in this part of the MD. In the Vietnamese part of the delta, flood compartments were represented by virtual canals and control structures presenting the dykes. The original model was later refined and updated by Manh et al. (2014) and Triet et al. (2017) (see Fig. 5). The model was calibrated and validated with gauged data and maximum inundation extents derived from satellite data for a number of flood events, including the moderate flood of 2009 , the low flood of 2010 , and the extreme floods in 2011 and 2000. For a detailed description of the 2-D model see the original paper by Dung et al. (2011).

\subsection{Transformation of water levels to flood hazard indicators}

The hydraulic simulations provided discharge and water level time series at the model calculation nodes. Inverse distance weighting (IDW) was applied to interpolate between nodes for complete spatial coverage. Inundation extent and depth were then obtained by intersecting the water levels with the lidar-based DEM.

Based on the rice cropping system and cropping calendar, three gridded inundation maps were produced for each simulation scenario. The first map, labelled "July", was generated using the maximum water level of 61 days from the beginning of simulation from 1 June to 31 July. It was applied to calculate damage to the summer-autumn crop (SAC) in both shallow- and deep-submergence regions. The second map (August) was based on the maximum water level from 1 June to 15 September in order to calculate damage to the autumn-winter crop (AWC) in the shallow-submergence region. For the AWC in the deep-submergence region, we used the map defined by the maximum annual submergence (annual) within 1 September to 30 November. The inundation grid cells of these maps were classified into three inundation depth classes to assign a stage-damage curve (Fig. 4c) to each grid cell. Exposed areas of rice crops were calculated by intersecting the inundation maps with the two land-use maps presenting the SAC and the AWC, as summarized in Table 1.

All these procedures were performed using Python scripts (Python version 2.7) and the Python-supported module of ArcGIS (ArcGIS 10.4).

\subsection{Calculation of flood damage $(D)$ and expected annual damage (EAD)}

Flood damage $(D)$ was calculated on a pixel basis following equation (Eq. 2) and aggregated to damage per province and to the whole study area.

$D=Y \times \mathrm{MP} \times\left(A_{1} \cdot \mathrm{RD}_{1}+A_{2} \cdot \mathrm{RD}_{2}\right)$,

where $D$ is the total monetary damage (in USD). $Y$ and MP are the average rice yield and market prices taken from official statistical data for 2011: $Y=5.0$ ton per hectare, and $\mathrm{MP}=\mathrm{USD} 280$ per ton. $A_{1}$ and $A_{2}$ are the total exposed areas classified as partial and full losses. $\mathrm{RD}_{1}$ and $\mathrm{RD}_{2}$ are the relative damage factors specified on the basis of the damage curves adopted from Dutta et al. (2003) (see Fig. 4c). The percentage of damage (i.e. in terms of yield reduction) depends on the duration of contact with floodwater (in days) and inundation depth, which was classified into two groups, i.e. below $0.5 \mathrm{~m}$ and above $0.5 \mathrm{~m}$. Because flooding in the VMD is characterized with a long duration of submergence of 2-5 months (Toan, 2014), loss factor $\mathrm{RD}_{2}$ was set to 1 for the areas where inundation depth is above $0.5 \mathrm{~m}\left(A_{2}\right)$, while the partial loss factor $\mathrm{RD}_{1}$ was set to 0.5 , which is the maxi- 

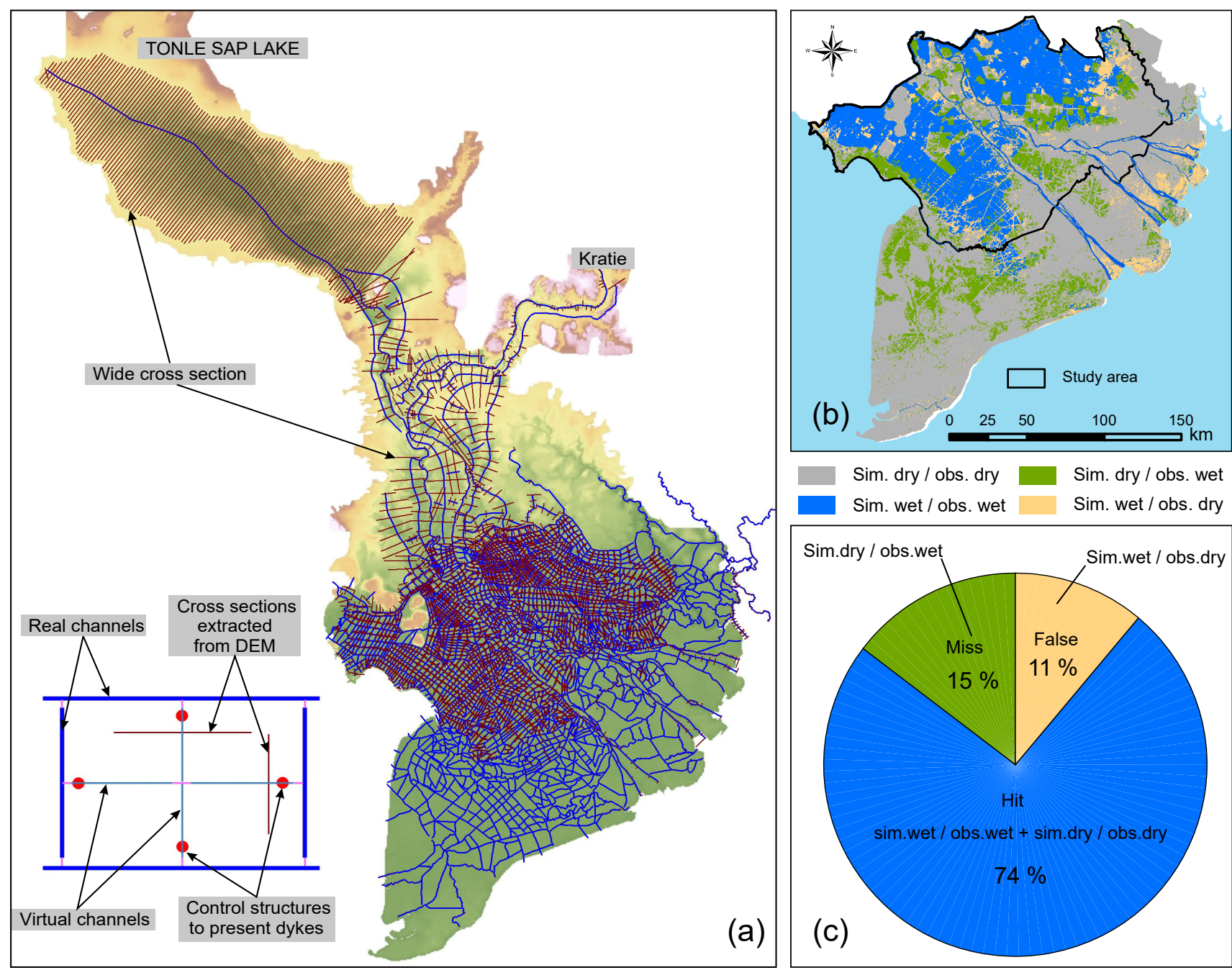

(a)

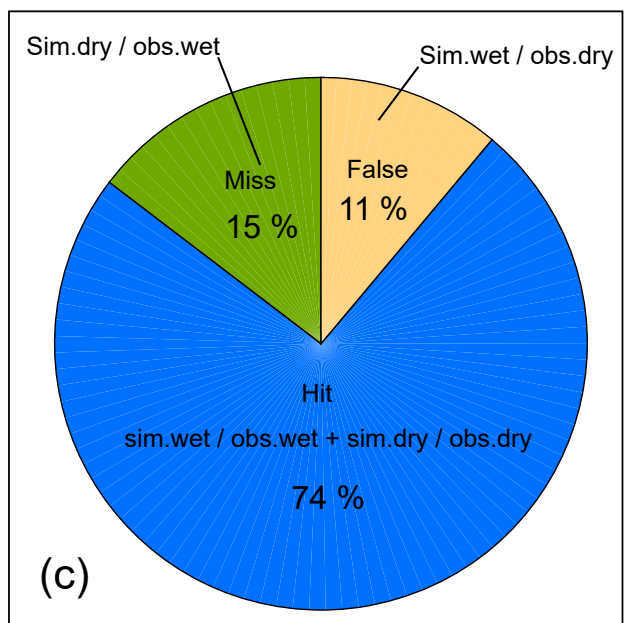

Figure 5. (a) Schematization of the quasi-2-D flood propagation model for the Mekong Delta and the concept of simulation of compartmented floodplains in the VMD. Comparison of observed inundation extent derived from satellite data and simulated maximum inundation extent for the flood event in 2011 for the whole delta (b), and evaluation of inundation simulation (c) adapted from Triet et al. (2017).

Table 1. Inundation maps for estimating damage to rice crops in the Vietnamese Mekong Delta.

\begin{tabular}{|c|c|c|c|c|c|}
\hline \multirow[t]{2}{*}{ Inundation region } & \multirow[t]{2}{*}{ Cropping system } & \multirow[t]{2}{*}{ Rice crop } & \multirow[t]{2}{*}{ Planting calendar } & \multicolumn{2}{|c|}{ Input inundated raster } \\
\hline & & & & raster name & period \\
\hline \multirow{3}{*}{$\begin{array}{l}\text { Shallow } \\
\text { (below } 1.5 \mathrm{~m} \text { ) }\end{array}$} & \multirow{3}{*}{$\begin{array}{l}\text { double-season rice } \\
\text { triple-season rice }\end{array}$} & Summer-autumn (SAC) & mid-April-mid-July & July & 1 Jun-31 Jul \\
\hline & & Summer-autumn (SAC) & March-May/early June & July & $1 \mathrm{Jun}-31 \mathrm{Jul}$ \\
\hline & & Autumn-winter (AWC) & mid-June-mid September & August & 1 Jun-15 Sep \\
\hline \multirow{3}{*}{$\begin{array}{l}\text { Deep } \\
\text { (above } 1.5 \mathrm{~m} \text { ) }\end{array}$} & \multirow{3}{*}{$\begin{array}{l}\text { double-season rice } \\
\text { triple-season rice }\end{array}$} & Summer-autumn (SAC) & May-July & July & 1 Jun-31 Jul \\
\hline & & Summer-autumn (SAC) & May-July & July & 1 Jun-31 Jul \\
\hline & & Autumn-winter (AWC) & September-November & Annual & $1 \mathrm{Sep}-30 \mathrm{Nov}$ \\
\hline
\end{tabular}

mum damage of this class in the damage functions, for areas with inundation depth below $0.5 \mathrm{~m}\left(A_{1}\right)$.
We calculated the EADs for each of the four hydrograph shapes following Apel et al. (2016). EAD is defined as the product of probability of exceedance of a given flood event 
and its damage:

$\mathrm{EAD}=\sum_{i=1}^{n} \Delta P_{i} \cdot \bar{D}_{i}$

$\Delta P_{i}$ and $\bar{D}_{i}$ are calculated as follows:

$\bar{D}_{i}=\frac{1}{2}\left(D_{i}+D_{i+1}\right)$

$\Delta P_{i}=p_{i+1}-p_{i}$,

where $\Delta P$ is the increment of annual probability of exceedance $=\Delta(1-p)$, with $p$ as the annual probability of non-exceedance. In this work $p=0.90,0.95,0.98$ and 0.99 according to the selected return periods; $D$ is the calculated damage induced by the given event; $i$ is the numerator of the probability levels considered, and $n$ is the number of probability levels.

The average estimated annual damage $(\overline{\mathrm{EAD}})$ of the four hydrograph shapes was computed as the weighed sum of the EAD values, with the probability of occurrence of the hydrograph (Pr) as weights (Eq. 6). The average crop risk indicator was computed by dividing the average EAD by the total annual rice plantation area.

$\overline{\mathrm{EAD}}=\sum_{i=1}^{4} \operatorname{Pr}\left(\operatorname{sh} \mathrm{p}=\operatorname{shp}_{i}\right) \mathrm{EAD}_{i}$

\subsection{Estimation of risk variation as a result of two land-use scenarios}

In the final step, we investigated how flood risk will change in two land-use scenarios. Triet et al. (2017) proved that the construction of high-dyke areas in the northern delta provinces An Giang and Dong Thap increased the flood hazard in the centre of the delta. Thus, the first scenario considers the opening of the sluice gates in the high-dyke areas in these two provinces to introduce floodwater to the paddy fields during the main flood period, September-October. In response to this change in the flood management the farming system also changes: farmlands with triple-season cropping are converted to double-season cropping, i.e. no cultivation of the AWC. The second scenario considers an expansion of high dykes, i.e. an increase in the height of the existing low dykes, in these two provinces to enlarge the area with triple rice crop production. This scenario follows the development scenario, the so-called "food production scenario", proposed in the Mekong Delta Plan (Deltares, 2013). Dyke height was increased using information of dyke elevation from neighbouring compartments and maximum water level of the historical flood in 2000, which was chosen as the design event for flood control infrastructures in the delta.

The flood propagation model simulated the 16 synthetic floods for these two dyke scenarios, while the lower boundary conditions were preserved as in 2011. Figure 6 exemplarily illustrates the simulated inundation extent for the 10 -year flood for three scenarios (current situation, expansion and removal of high dykes).

\section{Results and discussion}

\subsection{Validation of estimated damage}

The damage estimation was validated by comparing the estimated damage for the flood in 2011 with official damage data. The exposed cropping area was overestimated by $18 \%$, i.e. 32500 ha in comparison with a reported area of 27000 ha (Tinh, 2012). We estimated rice crop losses of USD 42.7 million. This number is equivalent to $81 \%$ of the reported agricultural damages from the National Steering Committee for Flood and Storm Prevention and Control (USD 52.8 million) (MRC, 2011). Flood damages to other agriculture crops and facilities, e.g. farmhouses, which were included in the reported damages (lumped into a single value categorized as agriculture losses), were not yet incorporated in the presented damage estimation. Considering that paddy rice is the predominant crop in the delta, it is very likely to share a large part of the reported losses. Paddy fields derived from the land-use LC2014 raster account for $72 \%$ of whole agriculture land within the focus area of this study (deep- and shallow-inundation areas). Assuming a linear distribution of damages in the lumped official reported damages with landuse proportion, it can be reasoned that the simulated damages are in the range of the reported. However, it has to be acknowledged that spatial distribution and market prices of different crops are likely to be important for the damage estimation. In any case, although not the ideal piece of information, the reported agriculture losses were the only available data with which to evaluate our rice crop damage calculation.

A large share of the overestimated exposed area of rice crops can be attributed to the simulated inundation extents, although efforts have been made to update, refine, and calibrate the model (Dung et al., 2011; Manh et al., 2014; Triet et al., 2017). The main source of uncertainty stems from the interpolation of 1-D model results to a 2-D raster, which could not be reduced even by the high-resolution lidar DEM. Triet et al. (2017) reported a flood area index (FAI) of 0.64 for the comparison of modelled and observed inundated areas for the whole VMD. The FAI was computed by dividing the sets of pixels presenting the intersection of observed and simulated inundation with the set of pixels presenting the union of observed and simulated (Eq. 3 in Aronica et al., 2002). This value increased to 0.74 only if the flood-prone area of the VMD was considered. According to Aronica et al. (2002), who suggested that a FAI higher than 0.7 is considered acceptable for an inundation simulation model, it can be concluded that the performance of the inundation model for the VMD is acceptable for the flood-prone area of the VMD, where the bulk of flood damages occur. 


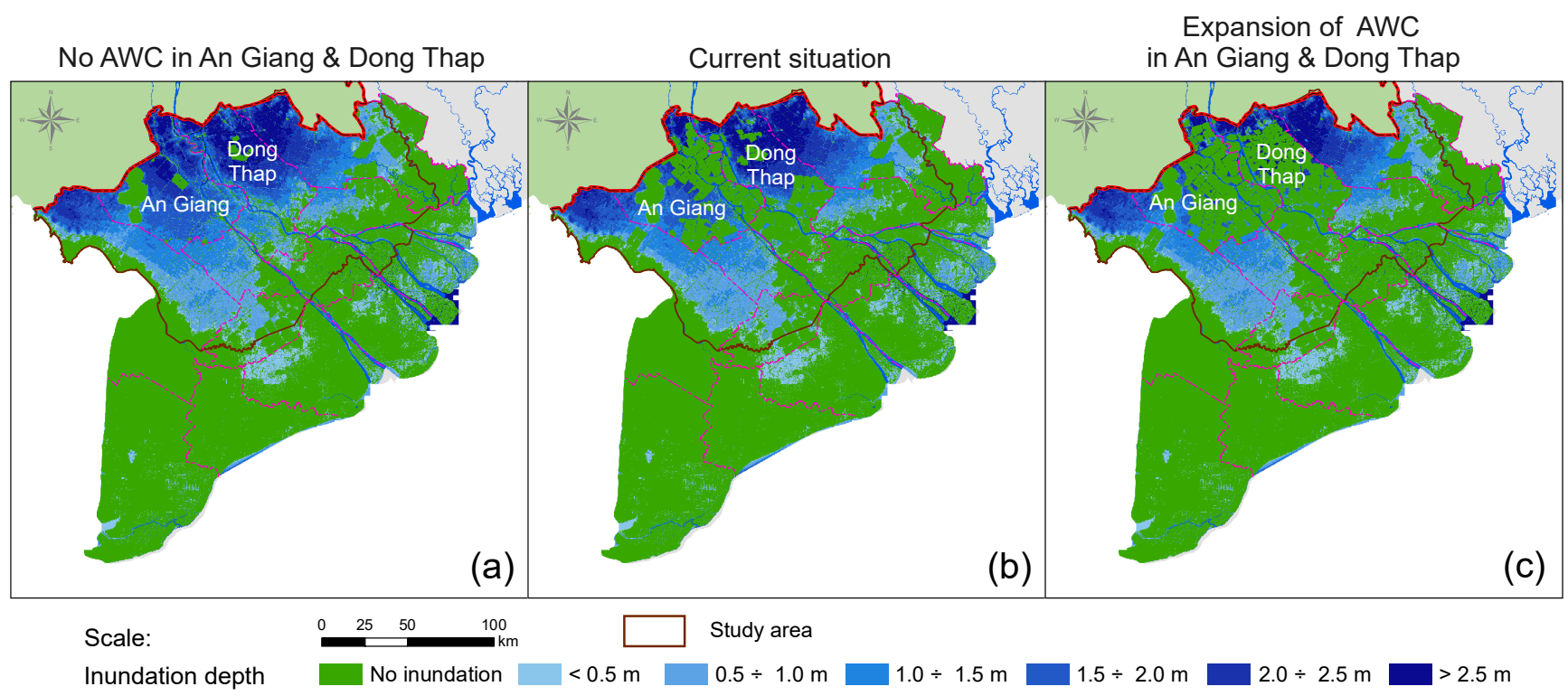

Figure 6. Simulated maximum inundation extent for a 10-year return period flood $\left(T_{10} \operatorname{shp}_{1}\right)$ for three land-use scenarios. (a) No plantation of autumn-winter crop in An Giang and Dong Thap, (b) present condition as of 2011, and (c) expansion of high-dyke areas in An Giang and Dong Thap to enlarge triple-season rice crops.

A small share of the overestimation of the 2011 flood might stem from the land-use data. Considering the rapid expansion of the triple-season rice areas in the delta (Le et al., 2018), it can be expected that the used land-use product of 2014 overestimates the spatial coverage of tripleseason rice paddies, possibly resulting in an overestimation of the flood damage. Also, land-use data have a resolution of $250 \times 250 \mathrm{~m}$; therefore the majority of inland canals (width $10-30 \mathrm{~m}$ ) were likely classified as rice pixels (see Fig. 3). Considered the channel density in the delta of $14 \mathrm{mha}^{-1}$ (Hung et al., 2012), not separating these inland water pixels might contribute with a small share to the overestimation. Additionally, other important factors were not considered, such as dyke failures and local flood management measures, i.e. early harvesting of rice crops despite not being $100 \%$ ripe or local raising of dyke segments with sandbags.

Some of these error sources might be resolved by further refining the model. For instance, the land-use data set can be improved by considering the inland canals when the crop areas are extracted. Enhancing model performance is, however, not that straightforward considering the huge amount of data required for the large-scale model domain. Despite these deficiencies, the flood damage assessment proposed in this study can produce reliable results, particularly when the typically large errors in flood damage estimation are taken as a reference (e.g. Schröter et al., 2014). Thus, the proposed method is judged to be appropriate to estimate flood hazard and risk to rice cropping in the VMD.

\subsection{Flood hazard assessment}

The flood event time series at Kratie were transformed into four hazard indicators: maximum water level, date of occurrence, inundation extent, and depth. The simulated annual maximum water levels (AMWLs) at locations with water level gauges in the VMD are summarized in Table 2. Figure 7 presents the date of occurrence (DO) of the AMWLs at these points. The chosen locations encompass nine gauges in the mainstream Mekong (i.e. Mekong River and Bassac River), and seven inland gauges in the two most important floodplains, i.e. LXQ (Long Xuyen Quadrangle) and PoR (Plain of Reeds). Inundated areas were calculated for the three periods specified in Table 1 and aggregated to the flood-prone area of the VMD on the basis of the four hydrograph shapes (Fig. 8).

The simulation results show that the AMWLs in the VMD vary substantially depending on flood magnitude $\left(T_{\mathrm{F}}\right)$ and hydrograph shapes. We estimated a relative change of $10 \%-$ $20 \%(40-60 \mathrm{~cm})$ in simulated AMWL for an event with $T_{100}$ compared to $T_{10}$ in the deep-submergence region (DSR), and $4 \%-8 \%(5-10 \mathrm{~cm})$ in the shallow-submergence region (SSR). The minor increase in the SSR can be attributed to the strong tidal influence at these stations. Hung et al. (2012) and Triet et al. (2017) reported a tidal influence of $70 \%$ $80 \%$ to the river flow and water level at Can Tho and My Thuan during the flood season. Towards the northern part of the VMD the tidal influence reduces to below $2 \%$ at Tan Chau and Chau Doc at the border with Cambodia (Hung et al., 2012). 

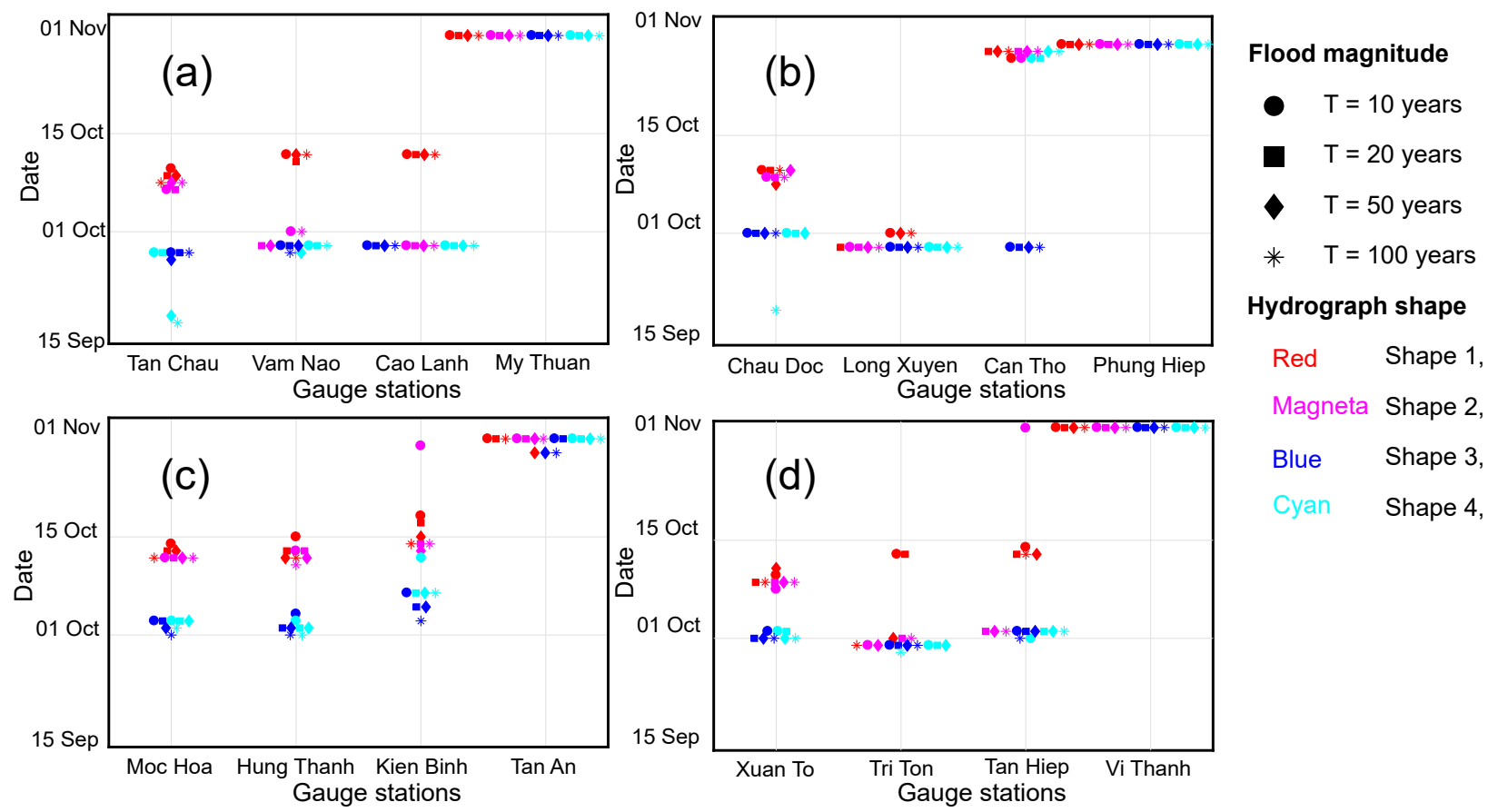

Hydrograph shape

Red Shape 1, p =21\%

Magneta Shape 2, $p=22 \%$

Blue

Shape 3, $p=34 \%$

Cyan Shape $4, p=23 \%$

Figure 7. Date of occurrence (DO) of the annual maximum water level at key monitoring gauges in the Vietnamese Mekong Delta (a) stations in the Mekong branch, (b) stations in the Bassac branch, (c) stations in the Plain of Reeds, and (d) stations in the Long Xuyen Quadrangle. The four hydrograph shapes (indicated by colours) are shown in combination with different flood magnitudes (indicated by markers).

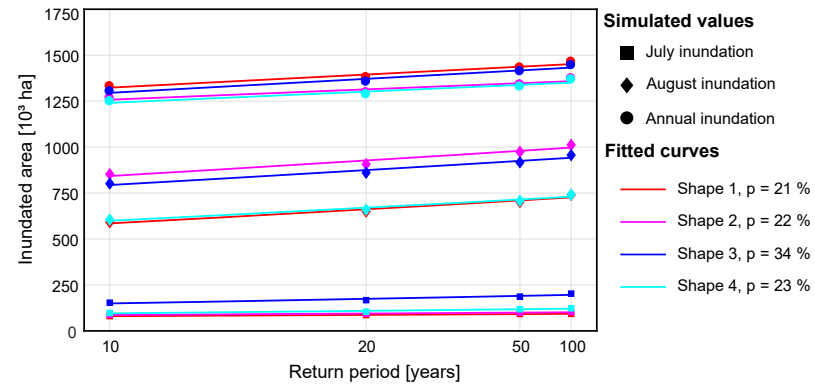

Figure 8. Frequency distributions of the maximum inundated area in July (squares), in August (diamonds), and over the whole year (circles) corresponding to the four flood patterns (different colours).

The hydrograph shape also influences the AMWL: higher AMWL were obtained for events with $\operatorname{shp}_{1}$ and $\operatorname{shp}_{3}$. The shape $\operatorname{shp}_{3}$ resulted in higher AMWL in the DSR, while $\operatorname{shp}_{1}$ yielded higher AMWL in the SSR of the delta. In contrast to this, $\operatorname{shp}_{2}$ and $\operatorname{shp}_{4}$ caused lower water levels. We found a difference in AMWL ranges from $9 \mathrm{~cm}$ at SSR to $45 \mathrm{~cm}$ at the DSR induced by the shapes $\operatorname{shp}_{2}$ and $\operatorname{shp}_{4}$ compared to the other two hydrograph shapes. These results are explained by the date of $Q_{\max }$ at Kratie: $\operatorname{shp}_{1}$ and $\operatorname{shp}_{3}$ have the second and higher peak in mid-September $\left(\mathrm{sh}_{3}\right)$ or mid-October $\left(\mathrm{shp}_{1}\right)$, about 1 month later than the other FP. When this peak is routed to the VMD, it already meets partly filled flood- plain compartments, and coincides with the period of highest tidal levels in the year (October-November). Therefore, the highest AMWL is caused by the hydrodynamic interaction between the upstream and downstream boundaries, and preceding inundation dynamics. Our simulation thus provides numerical evidence to confirm the statement in Tri (2012) and Triet et al. (2017) that the superposition of river flood peaks with high tide periods results in substantial backwater effects and higher water levels up to the border with Cambodia.

The date of occurrence (DO) of the AMWL in the VMD is less sensitive to changes in flood peak discharge and shape of hydrograph than the actual AMWL (see Fig. 7). The DO can be divided into two groups. The first group is composed of stations with prevailing tidal influence, e.g. Can Tho, My Thuan, and Vi Thanh. For this group AMWL occurs in late October, similarly to the period of maximum tidal levels in 2011, the downstream boundary conditions of the flood propagation model. The second group contains gauges further north or gauges far from the main rivers, where the tidal influence is largely reduced. These gauges have the DO in the first half of October.

Figure 8 illustrates the frequency distribution of maximum inundation extent for three periods: July, August, and the whole year. This indicator varies strongly depending on the hydrograph shapes. A 10-year flood event with hydrograph shape $\operatorname{shp}_{1}$ results in the same maximum extent as the 100- 


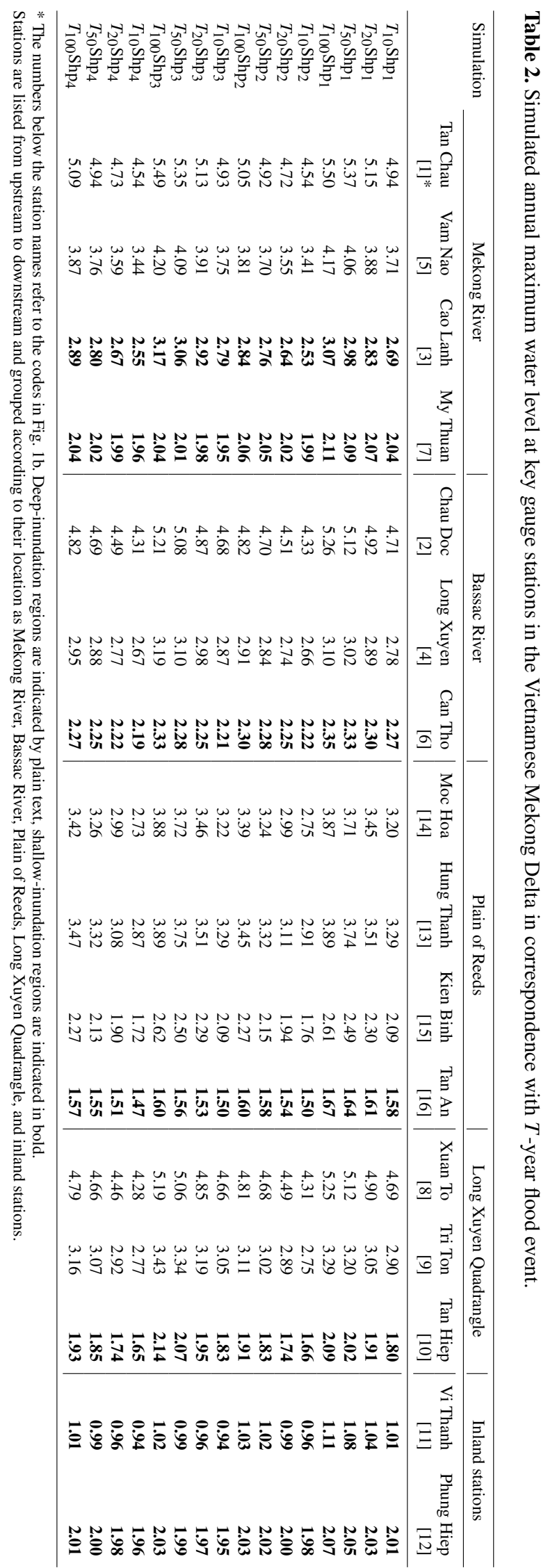

Nat. Hazards Earth Syst. Sci., 18, 2859-2876, 2018 year flood with $\mathrm{shp}_{4}$. This result proves the necessity to incorporate the temporal evolution of flood events into flood hazard and risk assessments in the MD. Our estimation of inundated areas from the $T_{10}$ to the $T_{100}$ event changed from $5 \%$ to $10 \%$ of the size of the flood-prone region of the VMD ( 2.0 million ha) in July, from $30 \%$ to $50 \%$ in August, and from $60 \%$ to $75 \%$ for the annual maximum extent. This means that even for the 100-year flood, $25 \%-40 \%$ of the flood-prone region was cut off from inundation by the implementation of high dykes, initiated after the flood in 2000.

\subsection{Exposed rice cropping area and flood damage}

Exposed areas and flood damage $(D)$ to rice crop were calculated on a pixel basis and then aggregated to the eight provinces located in the study area (Fig. 9 and Table 3). The average damage ranged from USD 39.0 million for a 10year flood to USD 75.0 million for a 100-year flood. These numbers account for $0.23 \%-0.45 \%$ of the total gross domestic product (GDP) of the eight provinces in 2011. Since such assessments are not available for neighbouring deltas in South Asia, e.g. Chao Phraya in Thailand or Irrawaddy in Myanmar, a comparison of these deltas is not possible. Our worst scenario, i.e. $T_{100} \mathrm{shp}_{3}$, resulted in damages of USD 115.7 million. This value is less than half of the reported overall damage of the flood in 2000 (USD 250 million; reported in MRC (2012), scaled to USD 500 million with 2011 price levels by Chinh et al., 2016), which is considered a 20-year flood in the MD (Le et al., 2007). Although the damage figures from the event in 2000 were the overall damages, of which agricultural damages were an unknown part, this indicates that a large reduction in flood losses can be linked to the flood management and adaptation measures being implemented in the VMD following the Decision No. 99/1996 from the Government of Vietnam (The Government of Viet Nam, 1996). Note that the plan was initiated in 1996, but was implemented to a large extent after the flood in 2000 had occurred.

The hydrograph shape has a substantial effect on damage to rice crops in the VMD. The shape $\operatorname{shp}_{3}$ resulted in a high amount of damage, roughly 1.5 times higher than the average damage. Flood hydrograph $\mathrm{shp}_{2}$ closely matched the average damage ( $85 \%-90 \%$ ), while $\mathrm{shp}_{1}$ and $\mathrm{shp}_{4}$ resulted in approximately $60 \%-70 \%$ of the average damage (Fig. $9 \mathrm{~b}$ ). These findings support our hazard and risk assessment approach and point to the relevance of the temporal evolution of the flood event for damage estimation. For example, the total flood damage from $T_{10} \mathrm{shp}_{3}$ (USD 57.8 million) was about $10 \%$ higher than the $T_{100} \mathrm{shp}_{1}$ event (USD 51.0 million).

The results provide evidence that rice cropping in the VMD is most vulnerable to flooding stemming from the early flood pulse in August-September when the total plantation area is expected to be at its maximum. During this period damage occurs to the second crop (SAC) in both DSR and SSR, and the AWC in the SSR. This finding is in line with 
Table 3. Flood damage to rice crop aggregated to the province level and converted to a percentage of the total damage.

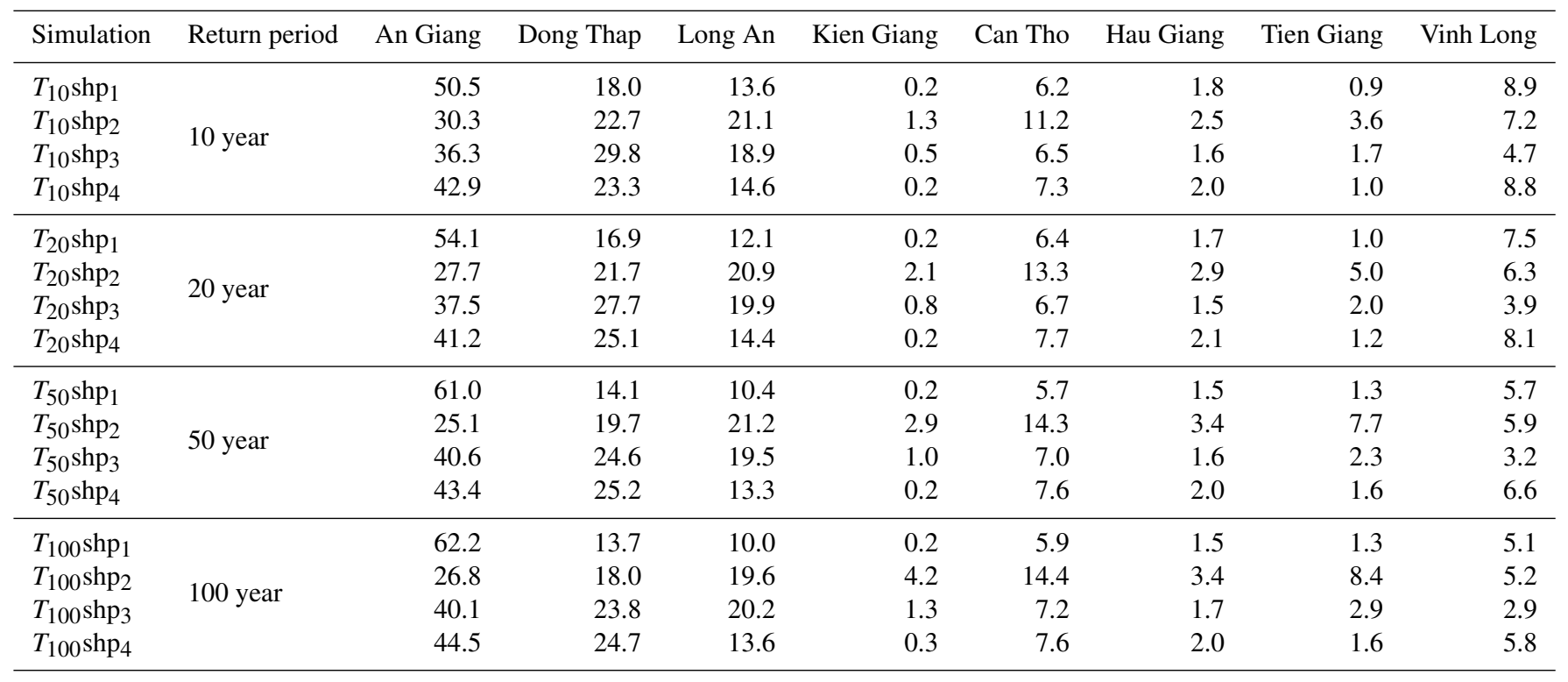
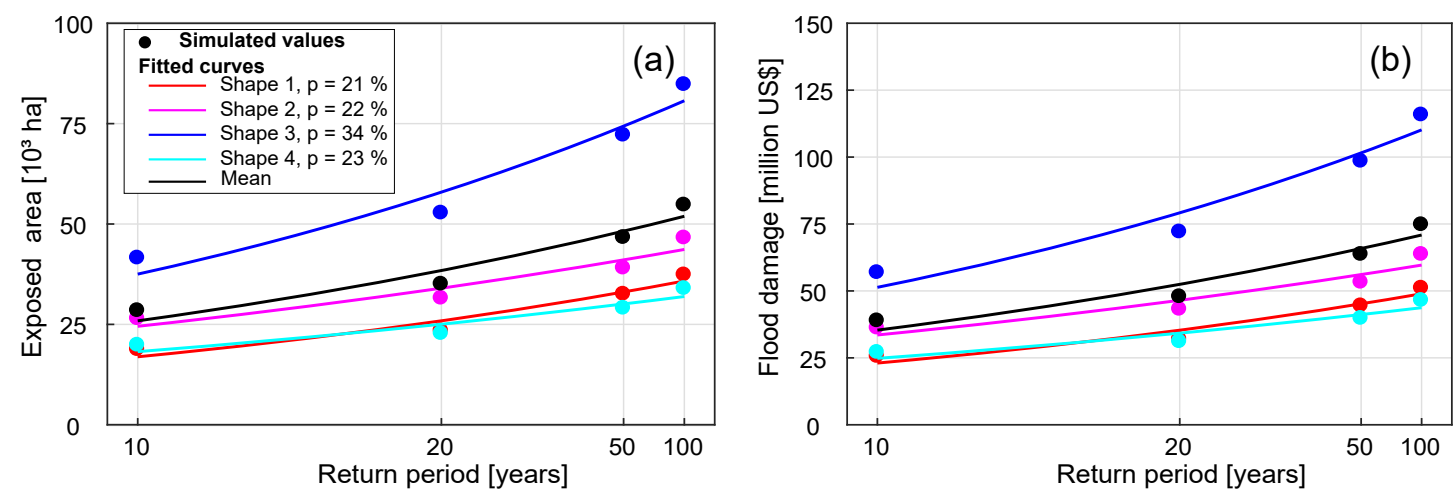

Figure 9. (a) Total exposed areas of rice crop in the Vietnamese Mekong Delta to floods of different return periods, calculated for the second and third rice crops and aggregated to the whole year. (b) Total damage for floods of different return periods.

the extremely high damages during the flood in 2000, which had a first peak at Tan Chau (point 1 in Fig. 1) on 2 August, i.e. 1 month earlier than usual (Xo et al., 2015). In contrast, damage from late flood events, i.e. $\mathrm{shp}_{1}$ or $\mathrm{shp}_{4}$, are limited to the AWC in the DSR due to failure of dyke structure, or flood levels overtopping the current dyke height, similar to the flood damages recorded in 2011.

Aggregating the mean $D$ values per province showed that the two northern provinces, An Giang and Dong Thap, accounted for about two-thirds of the total $D$ of the VMD, with flood damage in An Giang being about 1.5 times higher than in Dong Thap. This difference increases up to a factor of 3 in the case of late flood peaks (Table 3). This can be explained by the larger areas with triple rice crops in An Giang. This third crop in the DSR is particularly vulnerable to inundation in October-November (see Fig. 3b). Damages for the other two provinces in the DSR also showed remarkable differ- ences, with $\sim 16 \%$ of the total flood damage calculated for Long An located in the Plain of Reeds. This is 10-15 times higher than the share of Kien Giang ( $D$ in Kien Giang is less than $2 \%$ of the total $D$ ), although the rice cropping area is larger in Kien Giang (Bouvet and Le Toan, 2011; Nguyen et al., 2015).

The remaining SSR provinces accounted for about a quarter of the total $D$, which can be linked to their smaller rice cultivation areas in combination with their flood control measures. Our calculated flood damage to rice crop for Can Tho is, on average, in the range USD 2.9-6.3 million from the 10 -year to the 100 -year flood. These figures amount to about $60 \%$ of the estimated urban damages of Can Tho (USD 5.09.7 million) for events with similar magnitudes (Chinh et al., 2017). Since Can Tho has the highest urban/rural area ratio compared to the other delta provinces, it is likely that agri- 
culture losses have an equal or higher share in flood damages compared to urban losses in the other provinces of the delta.

\subsection{Rice cropping flood risk}

For the current land use, the EAD for rice cropping in the whole delta amounts to USD 4.5 million (see Fig. 10b), with an average crop risk of USD 1.0-4.6 for each unit of land [ha] (see Fig. 11a). The highest risk was calculated for the provinces located in the deep-submergence region (DSR), except for Kien Giang, where the EAD was very low.

An expansion of areas with triple rice cropping in An Giang and Dong Thap, as defined in the expansion development scenario, would increase the exposure to flooding. Figure 10b shows that this expansion of AWC would triple the EAD to above USD 15.0 million. The expansion of triple rice cropping also means that the current low-dyke system must be raised to a higher design level in order to support the cultivation of AWC during September-November. This, in turn, would lead to higher inundation hazards and risks in downstream provinces (Triet et al., 2017). Figure 11c shows both effects: a substantial increase in EAD in Dong Thap and An Giang, and a slight increase in EAD in the downstream provinces resulting from a higher-inundation hazard caused by the high-dyke development.

The second development scenario - introducing floodwater to the paddy fields after the SAC and no cultivation of AWC in An Giang and Dong Thap - resulted in smaller $D$ and EAD values, as expected. Abandoning AWC cultivation would result in an EAD decrease of about $40 \%$ (Fig. 10b). The majority of these changes in both scenarios stems from changes in An Giang and Dong Thap. The other provinces account for $5 \%-15 \%$ of the changes in EAD only.

The full flood control measures (high dykes) supporting the expansion of AWC areas in An Giang and Dong Thap after the flood in 2000 have been continuously debated. Triet et al. (2017) revealed that the change from low-dyke to highdyke systems in this upstream part of the delta increased the inundation hazard in downstream areas, e.g. by an increase of $9-13 \mathrm{~cm}$ in AMWL at Can Tho and My Thuan. Howie (2005) and Käkönen (2008) challenged the claim that farmers could have greater benefit by being able to add another harvest to the cropping system, because of more investment cost for mineral fertilizers to counter the losses of natural fertilization by deposited sediment (Manh et al., 2014), together with negative social and environmental consequences. The profitability of triple rice farming was reported to reduce from initially $57 \%$ to $6 \%$ after 15 years compared to double rice counterparts due to higher production costs (Tran et al., 2018). These arguments and findings might make the expansion of AWC less attractive.

On the other hand, rice cultivation areas in the southern part of the delta are likely to decrease due to increased salinity intrusion following higher sea levels (Smajgl et al., 2015; Hak et al., 2016) and land subsidence (Laura et al., 2014;
Minderhoud et al., 2017). Expansion of AWC in the northern part of the delta is an option for countering such losses and ensuring food security. Our results could support an evaluation of the costs and benefits of further high-dyke development and triple rice cropping expansion and thus provide important information for future flood management and landuse planning in the delta. Additionally, the damage and risks maps can serve as a basis for flood management. They could support the agricultural insurance, initiated in 2011 by the decision of the Prime Minister of Vietnam. In this programme the insurance premium depends on the rice yield only, and the spatial pattern of the flood hazard is not considered (The Government of Viet Nam, 2011).

\subsection{Uncertainties, limitation and future research directions}

One of the major sources of uncertainties in our estimation of $D$ and EAD is associated with the inundation maps. The process of interpolating from 1-D water levels to 2-D inundation raster inherits uncertainties from the hydraulic model and from the DEM used for interpolation (Brandt, 2016). A full 2-D modelling approach might enhance the quality of flood inundation mapping, but this comes at a cost: the setup of a full 2-D hydraulic model on that scale is challenging because of the high density of man-made channels and hydraulic infrastructure, which need to be implemented in the model with high accuracy to substantially improve the simulations. Additionally, model runtime becomes critical in detailed large-scale 2-D hydraulic simulations within a risk assessment requiring a large number of model simulations. Large-scale approaches building on coarse-resolution modelling with sub-grid parameterization (Sampson et al., 2015) still cannot provide sufficient accuracy to properly map the hydraulic dynamics in such a complex system with flat topography, where details matter a lot. However, refining this approach in high resolution, including all relevant hydraulic structures, and implementation in a highly parallelized environment (e.g. on GPUs) could provide a viable path for reducing the uncertainties in hydraulic modelling of the MD.

Another uncertainty source is the land-use maps used to quantify flood exposure of rice crops. The land-use raster was produced using satellite data from 2014; thus it is somewhat outdated considering the dynamics of agricultural land-use change in the MD. The area of triple-season rice has very likely increased from 2014 to the present. An updated and higher-resolution land-use data set would certainly provide more up-to-date results.

Another uncertainty source is the limited number of return periods used to calculate EAD. Ward et al. (2011) showed that the number and choice of the selected return periods can introduce a significant bias in the EAD estimates. They also pointed out the importance of considering damages to frequently occurring low damage floods, in line with the findings of Merz et al. (2009). However, as the agricultural sys- 

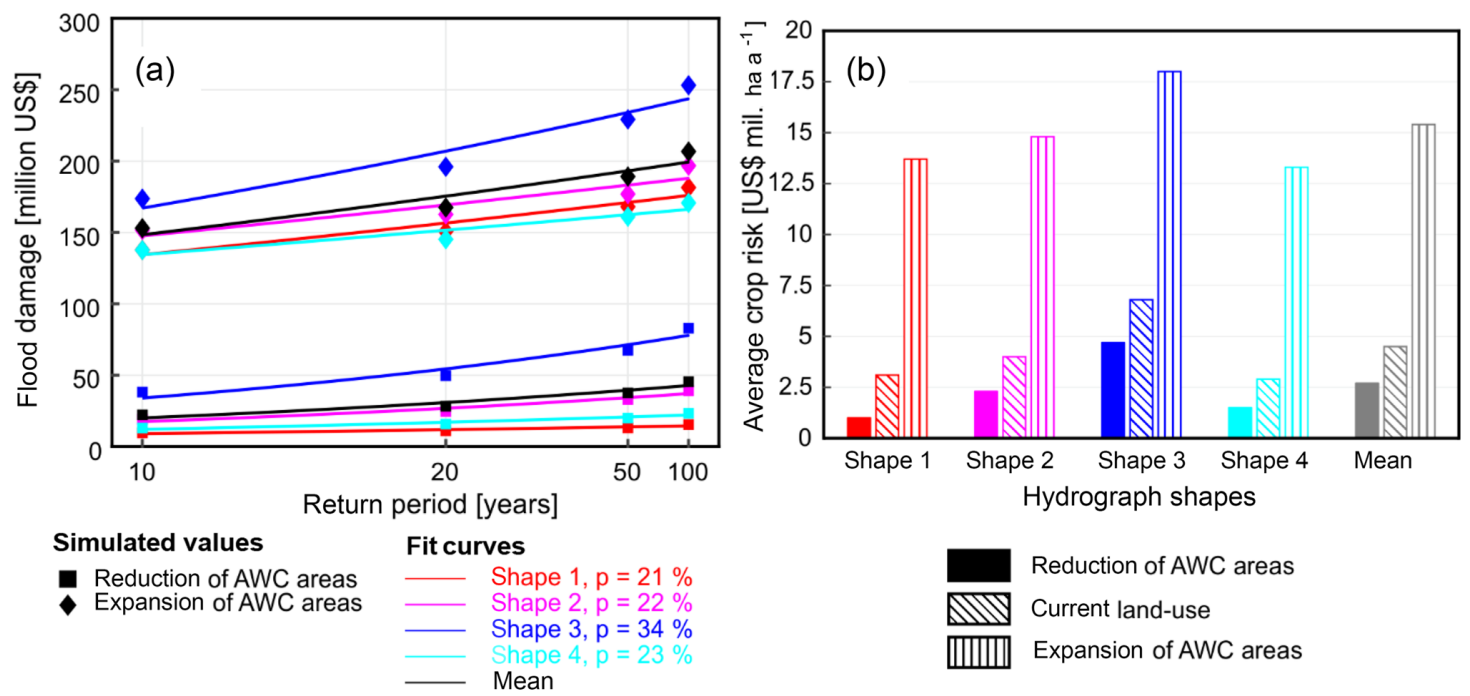

Figure 10. (a) Total flood damage for different return periods corresponding to two land-use scenarios. (b) Average crop risk as specific loss for each hydrograph shape.

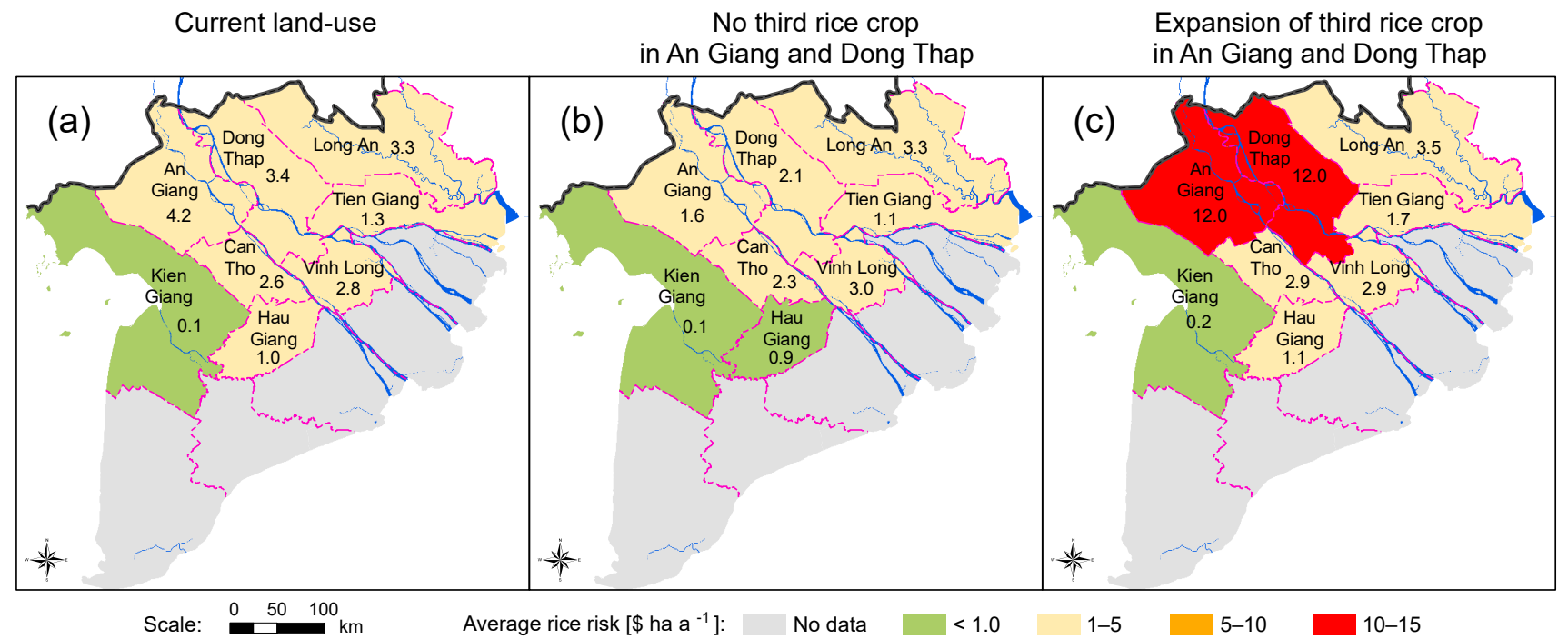

Figure 11. Flood risk for rice crops in the Vietnamese Mekong Delta. Specific loss is calculated in USD/ha/a for three land-use scenarios: (a) current land use, (b) no autumn-winter crop (AWC) in An Giang and Dong Thap, and (c) expansion of the AWC in these two provinces.

tem in the MD is well adapted to frequently occurring floods (in fact these floods are the basis for the current practice of paddy rice cropping), this effect is likely not as important as in the European studies listed above.

Our work does not consider flood damage to other agriculture crops (e.g. orchard farms) or land-use types (e.g. shrimp farms). Although these production types are smaller than rice cropping in terms of area, they generate much higher economic value per cultivation unit. Therefore, it is highly recommended to include these crops in future studies on agricultural flood risk in the VMD. To facilitate such assessments, efforts need to be made to collect data on crop and aquacul- ture type and area, plantation calendar, and their vulnerability to inundation. Such risk assessments could then be used for scenario planning by varying land-use types and cropping patterns or changing boundary conditions by climate change and upstream developments. In addition, dedicated efforts for validation and development of crop damage curves for the VMD based on recorded flood damages at the plot scale would increase the credibility of the presented risk analysis. Our study is validated against large scale, aggregated damage data only, and it is open to ensuring that small-scale variations, which could be important for local adaptation measures, are represented sufficiently well. 


\section{Conclusions}

A top-down approach to estimate flood damages and risks to rice cropping in the flood-prone areas of the Vietnamese Mekong Delta (VMD) is presented. The work was motivated by recent publications stating that extreme floods in the Mekong are likely to occur more frequently in the $21 \mathrm{st}$ century (Delgado et al., 2010; Hirabayashi et al., 2013), but also by the perceived need to shift flood management towards a risk-based approach. The presented quantification of flood risks to rice crops, the predominant land use in the region, is the first step in this direction, as a large-scale flood risk assessment has not been implemented to date. This work is thus the very first publication on a large-scale flood risk assessment for the agricultural sector in the VMD.

The results showed that the timing of the floods, the high tides and the cropping calendar are crucial factors for agricultural crop damage. Although the cropping calendars are adapted to the general flood dynamics in the different areas of the MD, large damages might still occur in the case of extreme events. A reliable seasonal forecast of the annual floods would thus be very helpful for a risk-based adaptive flood management of agricultural production. The study suggests that flood mitigation measures by the government and farmers, e.g. shifting of the cropping calendar and construction of dykes and sluice gates, before and after the historical flood in 2000 have greatly reduced potential agricultural flood damage.

The risk indicators, expected annual damage (EAD), and average crop risk per province can serve as the basis on which to develop spatially explicit flood management and mitigation plans for the delta. The crop risk maps, corresponding to two land-use change scenarios which are frequently used in the public and academic discussion, could be used as input for a cost-benefit analysis to evaluate the alternative of enlargement of the third rice crop in the two northern provinces.

Based on our findings, the following suggestions can be made to support flood management in the region: (1) appropriate maintenance is necessary for the flood control systems, with a strong emphasis on the low-dyke systems providing protection against the early flood wave before September. (2) The rice cropping scheme referred to as "ba nam tam vu", meaning eight rice crops every 3 years, should be reviewed. According to this scheme, sluice gates will be opened to allow floodwater to inundate the compartments in order to replenish the natural fertilization with deposited sediment at least once every 3 consecutive years. However, the study of Manh et al. (2014) revealed that during low flood years the estimated deposited sediment in the VMD was $\sim 14$ times smaller than in years of extreme floods. Thus, opening flood compartments during low flood year might result in little sediment deposition in paddy fields. We propose to open the flood compartments protected with high dykes in An Giang and Dong Thap during extreme events (i.e. larger than a 10year return period). However, for a proper implementation of such a scheme, a reliable seasonal forecasts of the expected floods are required. Our estimation of flood damage $(D)$ can be used as reference for developing such management plans based on a thorough cost-benefit analysis including a quantitative consideration of the benefits of natural fertilization vs. mineral fertilizers. (3) The current pilot programme on agriculture insurance should be revised, at least for rice cropping in the VMD. Insurance premiums are preferably calculated based on the average rice yield per province. Using our spatially explicit results would include the actual flood hazard of the insured area. However, the damages should be updated to current economic values, as the values of 2011 were used.

Finally, our inundation hazard maps can be used to quantify flood damages and risks to other agricultural crops and land use in the MD if appropriate land-use maps and damage models are available. In a similar manner changes in flood hazard and risk inflicted by impacts of climate change, sea level rise, the pronounced deltaic land subsidence, landuse changes, and upstream hydropower development can be quantified systematically. These issues will be addressed in future work.

Data availability. The data used in this paper are not publicly accessible; however, the authors can be contacted by email (triet@gfzpotsdam.de or heiko.apel@gfz-potsdam.de) for help in contacting the persons or authorities to acquire such data and how this should be acknowledged.

Author contributions. All authors contributed to the preparation of this paper.

Competing interests. The authors declare that they have no conflict of interest.

Special issue statement. This article is part of the special issue "Flood risk assessment and management". It is a result of the EGU General Assembly 2018, Vienna, Austria, 8-13 April 2018.

Acknowledgements. The work leading to this publication was supported by the German Academic Exchange Service (DAAD) with funds from the German Federal Ministry of Education and Research (BMBF). We acknowledge Akihiko Kotera at Vietnam Japan University for providing processed EVI data. The authors want to specially thank Pham The Vinh and various colleagues at SIWRR for their support in providing the DEM and survey data. We would like to thank Jorge Ramirez and the two anonymous referees who reviewed the manuscript for their comments and suggestions that helped to improve the paper.

The article processing charges for this open-access publication were covered by a Research 
Centre of the Helmholtz Association.

Edited by: Dhruvesh Patel

Reviewed by: Jorge Ramirez and two anonymous referees

\section{References}

Abbott, M. B. and Ionescu, F.: On the numerical computation of nearly horizontal flows, J. Hydraul. Res., 5, 97-117, 1967.

Apel, H., Martínez Trepat, O., Hung, N. N., Chinh, D. T., Merz, B., and Dung, N. V.: Combined fluvial and pluvial urban flood hazard analysis: concept development and application to Can Tho city, Mekong Delta, Vietnam, Nat. Hazards Earth Syst. Sci., 16, 941-961, https://doi.org/10.5194/nhess-16-941-2016, 2016.

Aronica, G., Bates, P., and Horritt, M.: Assessing the uncertainty in distributed model predictions using observed binary pattern information within GLUE, Hydrol. Process., 16, 2001-2016, 2002.

Bouvet, A. and Le Toan, T.: Use of ENVISAT/ASAR wideswath data for timely rice fields mapping in the Mekong River Delta, Remote Sens. Environ., 115, 1090-1101, https://doi.org/10.1016/j.rse.2010.12.014, 2011.

Bouvet, A., Le Toan, T., and Nguyen, L. D.: Monitoring of the Rice Cropping System in the Mekong Delta Using ENVISAT/ASAR Dual Polarization Data, IEEE T. Geosci. Remote, 47, 10, https://doi.org/10.1109/TGRS.2008.2007963, 2009.

Brandt, S. A.: Modeling and visualizing uncertainties of flood boundary delineation: algorithm for slope and DEM resolution dependencies of 1D hydraulic models, Stoch. Env. Res. Risk A., 30, 1677-1690, https://doi.org/10.1007/s00477-016-1212-z, 2016.

Chinh, D., Dung, N., Gain, A., and Kreibich, H.: Flood Loss Models and Risk Analysis for Private Households in Can Tho City, Vietnam, Water, 9, 313, 2017.

Chinh, D. T., Bubeck, P., Dung, N. V., and Kreibich, H.: The 2011 flood event in the Mekong Delta: preparedness, response, damage and recovery of private households and small businesses, Disasters, 40, 753-778, https://doi.org/10.1111/disa.12171, 2016.

Dang, T. D., Cochrane, T. A., Arias, M. E., and Tri, V. P. D.: Future hydrological alterations in the Mekong Delta under the impact of water resources development, land subsidence and sea level rise, J. Hydrol.-Regional Studies, 15, 119-133, https://doi.org/10.1016/j.ejrh.2017.12.002, 2018.

Delgado, J. M., Apel, H., and Merz, B.: Flood trends and variability in the Mekong river, Hydrol. Earth Syst. Sci., 14, 407-418, https://doi.org/10.5194/hess-14-407-2010, 2010.

Deltares: Mekong Delta Plan, Long-term vision and strategy for a safe, prosperous and sustainable delta, available at: https://www.deltares.nl/app/uploads/2014/01/ Mekong-delta-plan-Long-term-vision-and-strategy.pdf (last access: 20 July 2018), 126, 2013.

Dinh, Q., Balica, S., Popescu, I., and Jonoski, A.: Climate change impact on flood hazard, vulnerability and risk of the Long Xuyen Quadrangle in the Mekong Delta, International Journal of River Basin Management, 10, 103-120, 2012.

Dung, N. V., Merz, B., Bárdossy, A., Thang, T. D., and Apel, H.: Multi-objective automatic calibration of hydrodynamic models utilizing inundation maps and gauge data, Hydrol. Earth Syst.
Sci., 15, 1339-1354, https://doi.org/10.5194/hess-15-1339-2011, 2011.

Dung, N. V., Merz, B., Bárdossy, A., and Apel, H.: Handling uncertainty in bivariate quantile estimation - An application to flood hazard analysis in the Mekong Delta, J. Hydrol., 527, 704-717, 2015.

Dutta, D., Herath, S., and Musiake, K.: A mathematical model for flood loss estimation, J. Hydrol., 277, 24-49, 2003.

Förster, S., Kuhlmann, B., Lindenschmidt, K.-E., and Bronstert, A.: Assessing flood risk for a rural detention area, Nat. Hazards Earth Syst. Sci., 8, 311-322, https://doi.org/10.5194/nhess8-311-2008, 2008.

GSO: Statistical handbook of Vietnam 2015, General statistics office of Viet Nam, 2015.

Hak, D., Nadaoka, K., Patrick Bernado, L., Le Phu, V., Hong Quan, N., Quang Toan, T., Hieu Trung, N., Van Ni, D., and Pham Dang Tri, V.: Spatio-temporal variations of sea level around the Mekong Delta: their causes and consequences on the coastal environment, Hydrological Research Letters, 10, 60-66, 2016.

Hirabayashi, Y., Mahendran, R., Koirala, S., Konoshima, L., Yamazaki, D., Watanabe, S., Kim, H., and Kanae, S.: Global flood risk under climate change, Nat. Clim. Change, 3, 816, https://doi.org/10.1038/nclimate1911, 2013.

Howie, C.: High dykes in the Mekong Delta in Vietnam bring social gains and environmental pains, Aquaculture News, 32, 15-17, 2005.

Huete, A., Didan, K., Miura, T., Rodriguez, E. P., Gao, X., and Ferreira, L. G.: Overview of the radiometric and biophysical performance of the MODIS vegetation indices, Remote Sens. Environ., 83, 195-213, https://doi.org/10.1016/S0034-4257(02)00096-2, 2002.

Hung, N. N., Delgado, J. M., Tri, V. K., Hung, L. M., Merz, B., Bárdossy, A., and Apel, H.: Floodplain hydrology of the Mekong Delta, Vietnam, Hydrol. Process., 26, 674-686, https://doi.org/10.1002/hyp.8183, 2012.

Käkönen, M.: Mekong Delta at the crossroads: more control or adaptation?, AMBIO, 37, 205-212, 2008.

Klaus, S., Kreibich, H., Merz, B., Kuhlmann, B., and Schröter, K.: Large-scale, seasonal flood risk analysis for agricultural crops in Germany, Environ. Earth Sci., 75, 1289, https://doi.org/10.1007/s12665-016-6096-1, 2016.

Kotera, A., Nagano, T., Hanittinan, P., and Koontanakulvong, S.: Assessing the degree of flood damage to rice crops in the Chao Phraya delta, Thailand, using MODIS satellite imaging, Paddy Water Environ., 14, 271-280, 2016.

Laura, E. E., Steven, M. G., and Howard, A. Z.: Groundwater extraction, land subsidence, and sea-level rise in the Mekong Delta, Vietnam, Environmental Research Letters, 9, 084010, 2014.

Le, T. N., Bregt, A. K., van Halsema, G. E., Hellegers, P. J. G. J., and Nguyen, L.-D.: Interplay between landuse dynamics and changes in hydrological regime in the Vietnamese Mekong Delta, Land Use Policy, 73, 269-280, https://doi.org/10.1016/j.landusepol.2018.01.030, 2018.

Le, T. V. H., Nguyen, H. N., Wolanski, E., Tran, T. C., and Haruyama, S.: The combined impact on the flooding in Vietnam's Mekong River delta of local man-made structures, sea level rise, and dams upstream in the river catchment, Estuar. Coast. Shelf Sci., 71, 110-116, https://doi.org/10.1016/j.ecss.2006.08.021, 2007. 
Leinenkugel, P., Kuenzer, C., Oppelt, N., and Dech, S.: Characterisation of land surface phenology and land cover based on moderate resolution satellite data in cloud prone areas - A novel product for the Mekong Basin, Remote Sens. Environ., 136, 180-198, https://doi.org/10.1016/j.rse.2013.05.004, 2013.

Manh, N. V., Merz, B., and Apel, H.: Sedimentation monitoring including uncertainty analysis in complex floodplains: a case study in the Mekong Delta, Hydrol. Earth Syst. Sci., 17, 3039-3057, https://doi.org/10.5194/hess-17-3039-2013, 2013.

Manh, N. V., Dung, N. V., Hung, N. N., Merz, B., and Apel, H.: Large-scale suspended sediment transport and sediment deposition in the Mekong Delta, Hydrol. Earth Syst. Sci., 18, 30333053, https://doi.org/10.5194/hess-18-3033-2014, 2014.

Merz, B., Elmer, F., and Thieken, A. H.: Significance of "high probability/low damage" versus "low probability/high damage" flood events, Nat. Hazards Earth Syst. Sci., 9, 1033-1046, https://doi.org/10.5194/nhess-9-1033-2009, 2009.

Merz, B., Kreibich, H., Schwarze, R., and Thieken, A.: Review article "Assessment of economic flood damage", Nat. Hazards Earth Syst. Sci., 10, 1697-1724, https://doi.org/10.5194/nhess10-1697-2010, 2010.

Minderhoud, P. S. J., Erkens, G., Pham, V. H., Bui, V. T., Erban, L., Kooi, H., and Stouthamer, E.: Impacts of 25 years of groundwater extraction on subsidence in the Mekong delta, Vietnam, Environ. Res. Lett., 12, 064006, https://doi.org/10.1088/17489326/aa7146, 2017.

MRC: Flood Damages, Benefits and Flood Risk in Focal Areas, Mekong River Commission, 184 pp., 2009.

MRC: Flood situation report 2011, MRC Technical Paper No. 36, Mekong River Commission, Phnom Phenh, 57 pp., 2011.

MRC: The Impact and Management of Floods and Droughts in the Lower Mekong Basin and The Implications of Possible Climate Change, Mekong River Commission, 129 pp., 2012.

Nguyen, D. B., Clauss, K., Cao, S. M., Naeimi, V., Kuenzer, C., and Wagner, W.: Mapping Rice Seasonality in the Mekong Delta with Multi-Year Envisat ASAR WSM Data, Remote Sensing, 7, 15868-15893, https://doi.org/10.3390/rs71215808, 2015.

Penning-Rowsell, E. C., Wilson, T., and Centre, F. H. R.: The benefits of flood and coastal defence: techniques and data for 2003, Middlesex University, London, UK, 2003.

Sampson, C. C., Smith, A. M., Bates, P. B., Neal, J. C., Alfieri, L., and Freer, J. E.: A high-resolution global flood hazard model, Water Resour. Res., 51, 7358-7381, https://doi.org/10.1002/2015WR016954, 2015.

Schröter, K., Kreibich, H., Vogel, K., Riggelsen, C., Scherbaum, F., and Merz, B.: How useful are complex flood damage models?, Water Resour. Res., 50, 3378-3395, 2014.

Smajgl, A., Toan, T. Q., Nhan, D. K., Ward, J., Trung, N. H., Tri, L. Q., Tri, V. P. D., and Vu, P. T.: Responding to rising sea levels in the Mekong Delta, Nat. Clim. Change, 5, 167-174, https://doi.org/10.1038/nclimate2469, 2015.
The Government of Viet Nam: Decision No. 99/TTg on water resources, infrastructure and rural development plan for the Vietnamese Mekong Delta during the period 1996-2000, 1996 (in Vietnamese).

The Government of Viet Nam: Decision No. 315/TTg on pilot programme for agriculture insurance in Vietnam, 2011 (in Vietnamese).

Tinh, D. N.: 2011 flood lesson leraned in Vietnam, Presentation at 2012 South-East-Asia Flood Risk Reduction Forum, Vietnam, 19, 2012.

Toan, T. Q.: Climate Change and Sea Level Rise in the Mekong Delta: Flood, Tidal Inundation, Salinity Intrusion, and Irrigation Adaptation Methods, in: Coastal Disasters and Climate Change in Vietnam, edited by: Esteban, N. D. T., Hiroshi Takagi Miguel, Elsevier, Oxford, 199-218, 2014.

Tran, D. D., van Halsema, G., Hellegers, P. J. G. J., Ludwig, F., and Wyatt, A.: Questioning triple rice intensification on the Vietnamese mekong delta floodplains: An environmental and economic analysis of current land-use trends and alternatives, J. Environ. Manage., 217, 429-441, https://doi.org/10.1016/j.jenvman.2018.03.116, 2018.

Tri, V.: Hydrology and Hydraulic Infrastructure Systems in the Mekong Delta, Vietnam, in: The Mekong Delta System, edited by: Renaud, F. G. and Kuenzer, C., Springer Environmental Science and Engineering, Springer Netherlands, 49-81, 2012.

Triet, N. V. K., Dung, N. V., Fujii, H., Kummu, M., Merz, B., and Apel, H.: Has dyke development in the Vietnamese Mekong Delta shifted flood hazard downstream?, Hydrol. Earth Syst. Sci., 21, 3991-4010, https://doi.org/10.5194/hess-21-3991-2017, 2017.

Van, P. D. T., Popescu, I., van Griensven, A., Solomatine, D. P., Trung, N. H., and Green, A.: A study of the climate change impacts on fluvial flood propagation in the Vietnamese Mekong Delta, Hydrol. Earth Syst. Sci., 16, 4637-4649, https://doi.org/10.5194/hess-16-4637-2012, 2012.

Van, T. C.: Identification of sea level rise impacts on the Mekong Delta and orientation of adaptation activities, 2009.

Ward, P. J., de Moel, H., and Aerts, J. C. J. H.: How are flood risk estimates affected by the choice of return-periods?, Nat. Hazards Earth Syst. Sci., 11, 3181-3195, https://doi.org/10.5194/nhess11-3181-2011, 2011.

Xo, L. Q., Hien, N. X., Thanh, N. D., Ngoc, B., Khoi, N. H., Lam, D. T., Khoi, T. M., Tien, H. T., and Uyen, N. T.: Mekong Delta flood management plan to 2020 and 2030, Southern Institute of Water Resources Planning, Hochiminh City, Vietnam, 2015 (in Vietnamese). 